\title{
Hydraulic resistance to overland flow on surfaces with partially submerged vegetation
}

\author{
Jongho Kim, ${ }^{1}$ Valeriy Y. Ivanov, ${ }^{1}$ and Nikolaos D. Katopodes ${ }^{1}$ \\ Received 25 February 2012; revised 9 August 2012; accepted 17 September 2012; published 24 October 2012.
}

[1] This study investigates numerically the characteristics of upscaling the Manning resistance coefficient $\left(n_{t}\right)$ for areas covered by partially submerged vegetation elements, such as shrub or tree stems. A number of high-resolution hydrodynamic simulations were carried out corresponding to scenarios with different domain slopes $(S)$, inflow rates $(Q)$, bed roughness $\left(n_{b}\right)$, and vegetation cover fractions $\left(V_{f}\right)$. Using simulations performed at fine space-time scales, two methods were developed for computing the upscaled Manning coefficient, termed "Equivalent Roughness Surface (ERS)" and "Equivalent Friction Slope (EFS)." Results obtained with these two methods indicate that both yield highly correlated estimates of $n_{t}$. The effects of four independent variables $\left(V_{f}, S, Q\right.$, and $\left.n_{b}\right)$ on $n_{t}$ were further investigated. First, as $V_{f}$ increases, $n_{t}$ also grows. Second, two distinct modes of the relationship between $S$ and $n_{t}$ for a fixed $V_{f}$ and $Q$ emerge: a positive dependence at lowflow rates and a negative dependence at high-flow rates. For a fixed $V_{f}$ and $S$, two distinct modes of the relationship between $Q$ and $n_{t}$ are also identified: a positive dependence at mild domain slopes and a negative dependence at steep slopes. A regression analysis shows that the two conflicting trends can occur depending on whether the variability of flow depth with respect to $S$ (or $Q$ ) is greater than the ratio of $h$ and $S$ (or $Q$ ). Third, a rougher soil bed (i.e., larger values of $n_{b}$ ) implies a higher resistance due to vegetation. Last, the study argues that $n_{t}$ increases as $h$ increases and decreases as $V$ increases. A generic regression relation that includes all four of the above variables and the difference $n_{t}-n_{b}$ (i.e., the additional resistance due to partially submerged vegetation representing the sum of the form and wave resistances) was developed. The range of applicability of this relation is given by the following conditions: $V_{f} \leq 0.5,0.1 \leq S \leq 1.1$, and $0.0001 \leq Q \leq 0.01$. The difference $n_{t}-n_{b}$ computed from the developed regression relation was compared with estimates reported by five different studies. Furthermore, the simulated wave resistance coefficients were compared with those predicted from an equation in a previous study; the estimates were consistent in the range of experimental conditions for which the latter equation was developed. The relationship is sufficiently general and applicable to other flow conditions with partially submerged roughness elements.

Citation: Kim, J., V. Y. Ivanov, and N. D. Katopodes (2012), Hydraulic resistance to overland flow on surfaces with partially submerged vegetation, Water Resour. Res., 48, W10540, doi:10.1029/2012WR012047.

\section{Introduction}

[2] Hydraulic resistance to open-channel and overland flows is an important characteristic that needs to be represented properly in modeling runoff, flood routing and inundation, and soil erosion. Resistance estimation affects not only the accurate calculation of flow variables, such as the water depth, velocity, and shear stress, but also the

\footnotetext{
${ }^{1}$ Department of Civil and Environmental Engineering, University of Michigan, Ann Arbor, Michigan, USA.

Corresponding author: J. Kim, Department of Civil and Environmental Engineering, University of Michigan, Ann Arbor, MI 48103, USA. (kjongho@umich.edu)

(C)2012. American Geophysical Union. All Rights Reserved. 0043-1397/12/2012WR012047
}

prediction of their derivative outcomes, such as the time of concentration, flow distribution in a basin, the transport capacity, the total sediment yield, etc. The resistance of a surface can be characterized with several hydraulic roughness coefficients. The most widely used are the Manning roughness coefficient $(n)$, the Chezy resistance factor $(C)$, and the Darcy-Weisbach friction factor $(f)$. Manning's $n$ is most popular in hydrological and soil erosion models, while using the Darcy-Weisbach $f$ is more common than the other resistance formulations in experimental studies [Hessel et al., 2003]. Theoretically, hydraulic resistance can be divided into five components: surface (grain) resistance, form resistance, wave resistance, rain resistance, and bed-mobility resistance [Abrahams and Parsons, 1994; Hu and Abrahams, 2006; Smith et al., 2007].

[3] Numerous studies have performed field or laboratory experiments and theoretical analyses seeking ways to relate 
hydraulic characterization of flow to roughness coefficients. These studies tried to investigate a number of dimensionless variables in an attempt to find suitable relationships using various metrics such as the Reynolds number (Re), the Froude number $(F r)$, the characteristic roughness length (e.g., the ratio of depth to roughness element), domain slope $(S)$, and vegetation or obstacle cover fractions. Since early studies of overland flow, resistance was described by a roughness coefficient, in analogy to the resistance relations used to characterize flows in pipes. A relationship between the roughness coefficients and the Reynolds number (e.g., $f-R e$ ) has been well established for shallow overland flows as well as for flows in pipes and smooth channels [Chow, 1959; Emmett, 1970; Li and Shen, 1973; Phelps, 1975; Savat, 1980]. The $f$-Re relationship has a negative slope of 1.0 in the laminar flow regime [Blasius, 1913]; in turbulent flow, different $f-R e$ relationships are obtained, depending on the value of the relative roughness [Nikuradse, 1933]. These findings indicated that among several possible dimensionless variables, $R e$ has a predominant effect in quantifying the flow resistance in conditions where the flow completely submerges a plane bed with either a smooth or a rough surface. In such conditions, the roughness height is significantly smaller than the flow depth and the hydraulic resistance is dominated by the surface resistance component arising due to the presence of roughness elements beneath the flow surface.

[4] However, in conditions where the surface is covered by stones, organic litter, or stems of vegetation that protrude through the flow, the aforementioned $f$-Re relationships are not applicable. Other dimensionless variables (e.g., $F r$, relative roughness height, vegetation cover, etc.) may become more dominant, reflecting that the form and wave resistance can become the primary components of the total flow resistance [Emmett, 1970; Roels, 1984; Abrahams et al., 1986; Gilley and Finkner, 1991; Gilley et al., 1992b; Hirsch, 1996; Lawrence, 1997; 2000; Takken and Govers, 2000; Hu and Abrahams, 2006]. For example, Emmett [1970] was the first to emphasize the importance of form resistance caused by microtopography, which can significantly exceed the surface resistance. Roels [1984] and Abrahams et al. [1986] stated that the standard $f$-Re relationship is not ubiquitous: the $f-R e$ relationship can have a convex upward or a negatively sloping power law relation. These relationships can be attributed to the progressive inundation of roughness elements, implying that the surface configuration of the elements, and not just the flow state, becomes dominant in quantifying the resistance. Further, Gilley and Finkner [1991] presented a regression equation for predicting $f$ and $n$ by including the characteristic length scale, i.e., a "random roughness index" as the primary variable. Gilley et al. [1992b] suggested that $f$ is largely controlled by a measure of the gravel cover fraction. Hirsch [1996] developed a flow resistance model that explained flow conditions when the fraction of roughness elements was greater than $10 \%$ and $F r$ was greater than 0.5 .

[5] Recently, Lawrence [1997] further demonstrated the importance of other dimensionless variables in conditions of emerging vegetation and other types of obstacles protruding through the flow. Rather than using the Reynolds number, Lawrence [1997] advocated the use of the inundation ratio, $h / k$, as the ratio of the flow depth $h$ to the characteristic height of roughness elements $k$. Lawrence [1997] identified distinct flow regimes, such as partial and marginal inundation, and well-inundated flows, with various fractions of obstacles (hemispheres) placed in the flow. Depending on whether the flow depth $h$ was greater/smaller than the characteristic height $k$, Lawrence [1997] estimated $f$ as a function of the inundation ratio by using a drag model for the partial inundation, a mixing length model for the marginal inundation, and a rough turbulent flow formula for wellinundated flows. Since the estimation of the drag model showed an underestimation of flow resistance for the partial inundation case, Lawrence [2000] later modified the form drag model to obtain higher $f$ values by increasing the drag coefficient, which was negatively correlated with $h / k$.

[6] The modified model of Lawrence [2000] was successfully applied for the estimation of flow resistance for the case of marginal inundation, where roughness elements were randomly distributed and relatively uniform in size. However, when this model was applied under conditions differing from the setting under which the model was developed, such as complex flow geometries, the performance was not always satisfactory. Ferro [2003] tested the model using laboratory measurements and showed that the modified mixing length formulation provided accurate estimates, while the modified drag model resulted in a limited accuracy in estimating $f$. Takken and Govers [2000] also tested the partial inundation case of Lawrence [1997] and concluded that for situations with the complex configurations of roughness elements, a single independent variable (i.e., $h / k$ ) was insufficient to predict $f$. Thus, other variables, such as the flowrate, $F r$, and $R e$ need to be considered to fully characterize the flow resistance [Takken and Govers, 2000; Smart et al., 2002; Hu and Abrahams, 2006].

[7] In shrubland or forested hillslopes, typical flow depths are much smaller than the height of roughness elements such as vegetation stems and thus inundation ratios are very small. Such flow conditions generally prevail in hillslope hydrological dynamics. Characterization of flow for partially inundated conditions with a nonuniform distribution of roughness elements is therefore significant for modeling runoff routing and soil erosion. However, these flow conditions remain poorly characterized by empirical observations. For example, experimental data from previous studies (see Lawrence [1997, Figure 4] reporting data from eleven studies) are limited to partial inundation cases, i.e., most of the observed inundation ratios were between 0.1 and 1 .

[8] In order to establish a general relationship applicable to a wide range of conditions, numerical modeling based on the two-dimensional shallow-water equations was carried out in this study. The numerical simulations corresponded to overland flow on hillslopes covered with shrubby or woody vegetation. An application of a numerical model, as compared to field or experimental manipulations, provides several advantages. Specifically, in the case of small depths of overland flow (few $\mathrm{mm}$ to $\mathrm{cm}$ length scale), the minimum requirement of water depth for measuring the velocity with Acoustic Doppler velocimeters or electromagnetic current meters is not satisfied [Lawless and Robert, 2001]. When the requirements are satisfied, small depths still represent an issue in terms of measurement accuracy [Biron et al., 1998]. These difficulties result in large measurement errors 
in laboratory or field experiments. Furthermore, the determination of the friction (or energy) slope used in the calculation of roughness coefficients is also cumbersome. It can be normally substituted with the bed slope under uniform flow conditions, but it may not represent truthfully a spatially varying friction slope in situations with many protruding obstacles. Lastly, the difficulty of controlling conditions for high-flow rates prevents empirical observations in field and laboratory studies [e.g., Takken and Govers, 2000; Hessel et al., 2003]. For example, Takken and Govers [2000] used discharges ranging from $4.2 \times 10^{-6}$ to $2.7 \times 10^{-4} \mathrm{~m}^{3} \mathrm{~s}^{-1}$.

[9] High-resolution, hydrodynamic numerical simulations can overcome all of the above problems by specifying arbitrary flow conditions, including both high and low-flow rates that occur in real world situations. Using detailed simulations performed at fine space-time scales, the properties of the resistance coefficient at larger spatial scales can be investigated. In order to represent a system with tree/shrub stems, a sloped plane populated with "obstacle cells" that have infinitely long vertical dimension was designed. A number of scenarios with different domain slopes $(S)$, inflow rates $(Q)$, bed substrate roughness conditions $\left(n_{b}\right)$, and vegetation cover fractions $\left(V_{f}\right)$ were considered. Based on the simulation results, two methods were developed to obtain the upscaled Manning coefficient. A predictive equation was developed using multiple regression and dimensional analyses and verified with five different experimental data sets and a proposed wave resistance equation. Finally, the characteristic controls of several independent variables on the roughness coefficient are described and evaluated.

\section{Model Description and Simulation Setup}

\subsection{Model Description: tRIBS-OFM}

[10] Overland flow is one of the most important phenomena in the rainfall-runoff mechanism. Overland flow is described by the propagation of shallow water waves using three different formulations, i.e., the dynamic wave, the inertia-free, and the kinematic wave approximations [Katopodes, 1982]. Under specific circumstances, such as the case of partial inundation for a surface covered with stones or vegetation, the inertia and pressure terms in the momentum equations are relatively significant, and thus only the dynamic wave formulation should be adopted for simulations. The model used in this study is the Triangulated Irregular Network (TIN)-Based Real Time Integrated Basin Simulator (tRIBS) and Overland Flow Model (OFM). The tRIBS-OFM is a coupled model consisting of a hydrologic model and a hydrodynamic model that can solve the two-dimensional SaintVenant (S-V) equations [Anderson, 1995] on an unstructured triangular grid, as well as consider the hydrological processes such as runoff generation, infiltration, etc. [Kim et al., 2012]. Since tRIBS-OFM can accurately calculate the inertia, pressure, gravity, and friction terms without restrictions of applicability, this model is able to capture the phenomena of backwater and diverging-converging thread as well as a noticeable change of flow variables (e.g., hydraulic jump). For a more detailed description, the reader is referred to Ivanov et al. [2004], Begnudelli and Sanders [2006], and Kim et al. [2012].

[11] One logical question is whether a simplified form of the Navier-Stokes equations, the Saint-Venant shallow water equations, is an adequate approximation for simulating flows of relatively small depth and flows passing in narrow openings between vegetation stems. Specifically, the first possible concern is whether the $\mathrm{S}-\mathrm{V}$ equations can accurately simulate very shallow flows. Such flows can be affected by both bottom boundary layer and free surface movement, and the vertically averaged S-V equations cannot recognize these effects of bottom/free surface boundaries. However, the major assumption in applying the $\mathrm{S}-\mathrm{V}$ equations is that depth (i.e., the vertical direction scale) should be much smaller than the length scale of a flow phenomenon in the horizontal direction. In an overland flow condition with small depths and a large spatial scale of the domain, this assumption is quite acceptable. A second concern is whether the Manning's parameterization used in the $\mathrm{S}-\mathrm{V}$ equations can adequately capture the energy loss due to eddies generated around plant stems. Three-dimensional turbulence modeling would appear to be a more suitable method that can consider such effects and thus reduce the uncertainty of simplifying assumptions of the S-V model. However, the application of turbulence models presents a number of challenges. First, several parameters still need to be determined to close a system of turbulence equations, e.g., k-epsilon, k-omega, SST, etc. for RANS models or Smagorinsky constant in LES models. Second, in order to accurately resolve turbulent eddies, appropriate representation scales have to be used and very fine mesh resolutions are necessary; as a "rule of thumb," mesh resolution has to be at least 1 order of magnitude finer than the effective eddy scale. For example, Stoesser et al. [2010] used time steps satisfying the CFL condition of 0.5 and a very fine mesh with nearly $30,000,000$ grid points for a simulation case with only 64 isolated stems. Although this study presented detailed results demonstrating various turbulent characteristics, extending this approach to higher Reynolds numbers and randomly distributed vegetation of a high cover fraction is not feasible. This would require much finer space-time scales of representation.

\subsection{Simulation Setup}

[12] For the estimation of Manning's $n$ for overland flow, numerical simulations are carried out for an inclined plane that is $1 \mathrm{~m}$ wide and $2 \mathrm{~m}$ long, using slopes ranging from 10 to $110 \%\left(5.7\right.$ to $\left.47.7^{\circ}\right)$ at the $20 \%$ resolution of the slope. Such a range of bed slopes represents possible hillslopes in a real watershed. The forcing for the domain is specified in two forms: as a spatially uniform rainfall of 10 $\mathrm{mm} \mathrm{h}^{-1}$ continuous intensity over the entire duration of the simulation and inflow rates of $0.0001,0.0005,0.001$, and $0.01 \mathrm{~m}^{3} \mathrm{~s}^{-1}$ uniformly distributed over the width of the upstream boundary. The inflow rates were selected so as to describe a variety of cases of hillslope hydrology. Specifically, the discharges of $0.0001,0.001$ and $0.01 \mathrm{~m}^{3} \mathrm{~s}^{-1}$ represent steady state flow rates at different locations of a hypothetical $1-\mathrm{m}$ wide planar slope at 10,100 , and $1000 \mathrm{~m}$ downstream of the upstream boundary, assuming $36 \mathrm{~mm} \mathrm{~h}^{-1}$ excess rainfall (e.g., the kinematic wave solution yields $0.0001 \mathrm{~m}^{3} \mathrm{~s}^{-1}$ steady state flowrate at the bottom of a $10 \mathrm{~m}$ hillslope as, etc.).

[13] Manning's coefficients of $0.02,0.03$, and 0.04 were chosen so as to represent a bare, rough plane surface without vegetation. These will be referred to as "the base 
Manning's coefficients" and denoted by $n_{b}$. The values of $n_{b}$ are used to represent various characteristics of bed, such as the particle size and distribution, the roughness height, and the degree of tillage. For example, a small value of $n_{b}$ corresponds to an experimental condition of bare sand, while a larger value is a representation of the condition with irregular depressions and heavy protruding stones. These constant base Manning coefficients only explain the resistance caused by friction at the flow bottom and are within a range of values reported in literature.

[14] Vegetation cover fractions (defined here as the fractional areas of nonsubmerged "stems," $V_{f}$ ) of $0,5,10,20$, 30 , and $50 \%$ were used. The locations of vegetation stems were determined randomly within the simulation domain for a given $V_{f}$ (see Figure 1). From a computational standpoint, each stem of vegetation is represented as a rigid, infinitely long wall of hexagonal shape composed of six triangles. The shape can be fit within a circle that has a diameter of approximately $2 \mathrm{~cm}$. Since for most practical situations the order of depths represented by the partial inundation is very small as compared to the stem height of plants, the assumption of a rigid, infinitely high wall is reasonable. The free-slip boundary condition is applied to the boundary of each stem cell, enforcing that the velocity normal to the cell interface is zero. Inside stem cells, depth and velocity are consequently forced to be zero.

[15] The mesh spacing used to represent the simulation domain is $0.01 \mathrm{~m}$ and the number of mesh nodes (vertices) and triangular cells is 20,201 and 40,000, respectively. The size of mesh is appropriate for representing the shape of a vegetation stem. The time step during the simulation time of $2 \mathrm{~min}$ is $0.002 \mathrm{sec}$ for the three low-inflow rates and $0.0005 \mathrm{sec}$ for the high inflow rate. The time step used is restricted by the Courant-Friedrichs-Lewy (CFL) condition that ensures the stability of the explicit numerical scheme [ Kim et al., 2012]. An impervious soil surface condition is assumed to exclude the processes of infiltration and subsurface flow.
While the latter impact surface runoff generation, the aim of the study is to investigate the effects of unsubmerged obstacles on the flow process in conditions of clearly identifiable independent variables; the impact of runoff-generating processes is indirectly accounted for through the boundary inflow rate.

[16] Simulation cases are designed so that the following characteristics are varied: vegetation cover fraction $\left(V_{f}\right)$, plane slope $(S)$, base Manning's coefficient $\left(n_{b}\right)$, and inflow rate $(Q)$. Preliminary simulations demonstrated that the effects of rainfall intensity were very minor, as compared to an inflow rate. Therefore, only a single rainfall scenario $\left(10 \mathrm{~mm} \mathrm{~h}^{-1}\right)$ was used.

\section{Methods for Determining a Representative Value of Resistance Coefficient}

[17] This section describes methodologies of obtaining the upscaled values of the total surface resistance $\left(n_{t}\right)$ based on the results of numerical simulations. Two methods for estimating $n_{t}$, the "Equivalent Roughness Surface" (ERS) and the "Equivalent Friction Slope" (EFS), are presented in the following. The essential difference between the ERS and EFS methods is whether information at internal data points is used for the computation of roughness, and the two methods contain their advantages and disadvantages. As opposed to EFS, the ERS method does not require any computations for the internal information but relies on a relationship between the time of concentration of the flow and the Manning coefficient of a bare, rough plane surface without vegetation for a given inflow rate and plane slope. The relationship should be determined beforehand and thus additional simulations are necessary if a slope or a flowrate is changed.

\subsection{Equivalent Roughness Surface}

[18] One method to obtain an upscaled value of roughness is by using an "Equivalent Roughness Surface" method. (a)

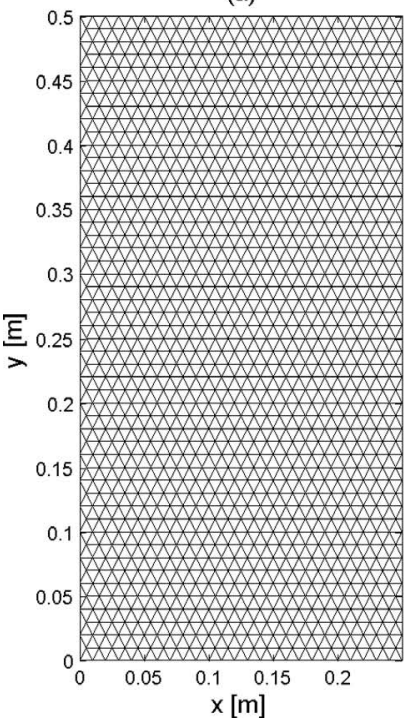

(b) upstream

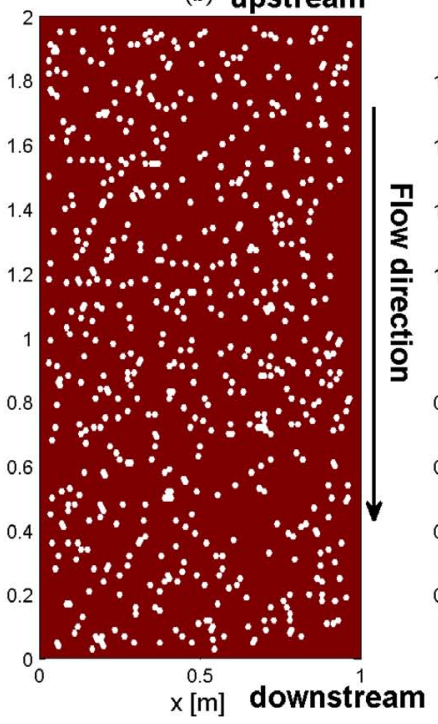

(c)

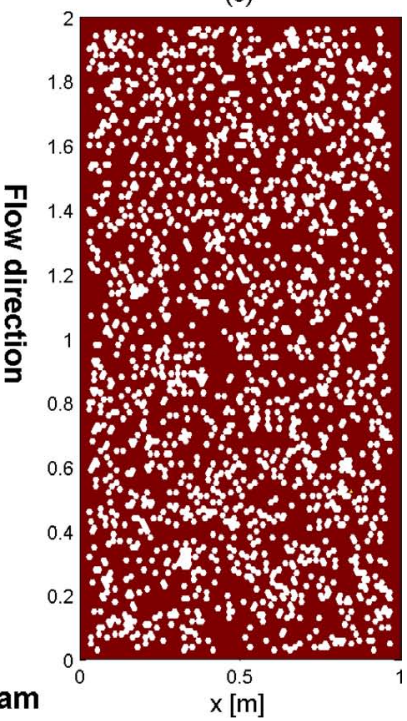

Figure 1. Illustrations of the simulation domain showing (a) triangular cells (zoomed-in) and locations of vegetation stems corresponding to the (b) $10 \%$ and (c) $30 \%$ vegetation cover cases. Each stem has a hexagonal shape consisting of six triangular cells. 
This method assumes that the resistance of a rough plane bed without vegetation stems is equal to the resistance of a smooth plane covered with vegetation stems. In other words, the effect of the form and wave resistances generated by internal obstacles (i.e., stems in this study) is considered to exert the same effect as the surface resistance of a rougher bed without vegetation. This method finds an equivalent resistance by analyzing the hydrographs at an outlet region; specifically, it compares the times of concentration $\left(t_{c}\right)$ of the simulated hydrographs for the flow case with vegetation stems and the case of flow over a rough, bare soil plane without any unsubmerged obstacles. When $t_{c}$ is matched, the two hydrographs corresponding to these flow situations are nearly identical.

[19] The determination of $t_{c}$ corresponding to the simulated hydrographs plays a crucial role in computing $n_{t}$. In this study, $t_{c}$ is defined as the time that satisfies the following two criteria:

$$
\frac{d Q\left(t_{c}\right)}{d t}<\in \text { and } Q\left(t_{c}\right)>0.95 Q_{\text {steady }},
$$

where $t$ is time; $Q(t)$ is discharge at time $t ; Q_{\text {steady }}$ is the theoretical discharge at steady state, equal to the upstream inflow rate plus the rainfall contribution; $\epsilon$ is a tolerance value assumed to be $10^{-5}$ in this study. The above criteria are chosen to avoid numerically unrealistic values in $t_{c}$ estimation.

[20] The derived relationship between $t_{c}$ and $n$ (see section 4.2) was assumed to be linear within intervals between the simulated cases. The relationship was used to find $n_{t}$ for any arbitrary $t_{c}$ through interpolation. To make the assumption of linearity valid, numerous simulations with small increments of $n$ were performed for the bare plane conditions, spanning a wide possible range of $t_{c}$ values.

\subsection{Equivalent Friction Slope}

[21] The second method used in this study uses an "Equivalent Friction Slope". It is based on information simulated at internal points and computes an average value of resistance that represents an upscaled value for the entire simulation domain. In order to obtain the value of $n$, the Manning's equation is rearranged:

$$
n=\frac{R^{2 / 3} S_{f}^{1 / 2}}{V}
$$

where $R$ is the hydraulic radius that can be replaced by the water depth, $h$, under the sheet flow assumption; $V$ is the flow velocity, calculated as $\sqrt{u^{2}+v^{2}} ; u$ and $v$ are $x$ and $y$ directional depth-averaged velocities, respectively; $S_{f}$ is the friction slope. The energy slope is typically replaced with the bottom slope for uniform flow. However, using the channel bottom slope is not appropriate in the case when protruding vegetation or other obstacles exist. Thus, the components of the friction slope are calculated as

$$
\begin{aligned}
& S_{f, x}=-\frac{\partial}{\partial x}\left(z_{b}+h+\frac{u \sqrt{u^{2}+v^{2}}}{2 g}\right), \\
& S_{f, y}=-\frac{\partial}{\partial x}\left(z_{b}+h+\frac{v \sqrt{u^{2}+v^{2}}}{2 g}\right),
\end{aligned}
$$

where $S_{f, x}$ and $S_{f, y}$ are the $x$ and $y$ directional energy slope components; $z_{b}$ is the bed elevation; $g$ is the acceleration due to gravity; and, finally, $S_{f}$ is calculated as $\sqrt{S_{f, x}^{2}+S_{f, y}^{2}}$. The terms in the above friction slope equations represent gravitational, pressure, and inertial forces, respectively. Introducing a new variable, $E_{x}=z_{b}+h+\frac{u \sqrt{u^{2}+v^{2}}}{2 g}$, its gradient can be calculated numerically from the following equation:

$$
\int_{A} \frac{\partial E_{x}}{\partial x} d A=\frac{\partial E_{x}}{\partial x} A
$$

under the assumption that the gradient of $E_{x}$ is constant inside a triangle cell with an area of $A$. When Green's theorem is applied in order to transform the area integral on the left-hand side of equation (4) to a line integral, $E_{x}$ is integrated along the cell boundaries. Thus, the $x$ directional friction slope becomes

$$
\frac{\partial E_{x}}{\partial x}=\frac{\left(y_{2}-y_{0}\right)\left(E_{x, 1}-E_{x, 0}\right)-\left(y_{1}-y_{0}\right)\left(E_{x, 2}-E_{x, 0}\right)}{\left(y_{2}-y_{0}\right)\left(x_{1}-x_{0}\right)-\left(y_{1}-y_{0}\right)\left(x_{2}-x_{0}\right)},
$$

where the subscripts " 0 ", " 1 ", and " 2 " are used to denote the three counterclockwise vertices of a triangle cell [ Kim et al., 2012]. The $y$ directional component is obtained in a similar fashion. Once the numerical model solves the mass and momentum equations of the flow, one can obtain the primary flow variables such as $h, u$, and $v$ at any point of the flow domain. Then, the upscaled value of $n$ for the entire domain can be computed by using the mean values of $h, V$, and $S_{f}$ obtained at steady state:

$$
n_{t}=\bar{h}^{2 / 3} \bar{S}_{f}^{1 / 2} \bar{V}
$$

where $n_{t}$ is the upscaled value of $n ; \bar{h}$ and $\bar{S}_{f}$ are the means of depth and friction slope for all triangle cells of the flow domain; $\bar{V}$ is calculated by dividing the unit discharge $(q)$ by the mean depth $(\bar{h})$. This approach relies on an assumption that the representative value of $S_{f}$ for the whole domain can be determined by averaging the corresponding local values. Since $\bar{S}_{f}$ avoids negative values because of the square root operation on the sum of its squared $x$ and $y$ components, it does not loose information on the variability of local friction slopes; this would be the case if a simple arithmetic averaging of negative and positive values were carried out.

\section{Simulation Results}

\subsection{Overall Characterization of Flow Variables}

[22] Flow characteristics are first analyzed. Figure 2 shows the spatial distribution of different flow variables such as depth, velocity, and friction slope at steady state for the case of $S=30 \%, n_{b}=0.02$, and $Q=0.001 \mathrm{~m}^{3} \mathrm{~s}^{-1}$. The spatial distributions for the cases of bare soil and vegetated soil with $V_{f}=30 \%$ are compared. In the case of bare soil with these fairly large $S$ and $Q$, the flow approaches a uniform state with a depth of $0.0022 \mathrm{~m}$ and a velocity of $0.455 \mathrm{~m} \mathrm{~s}^{-1}$. These numerical values are also consistent 

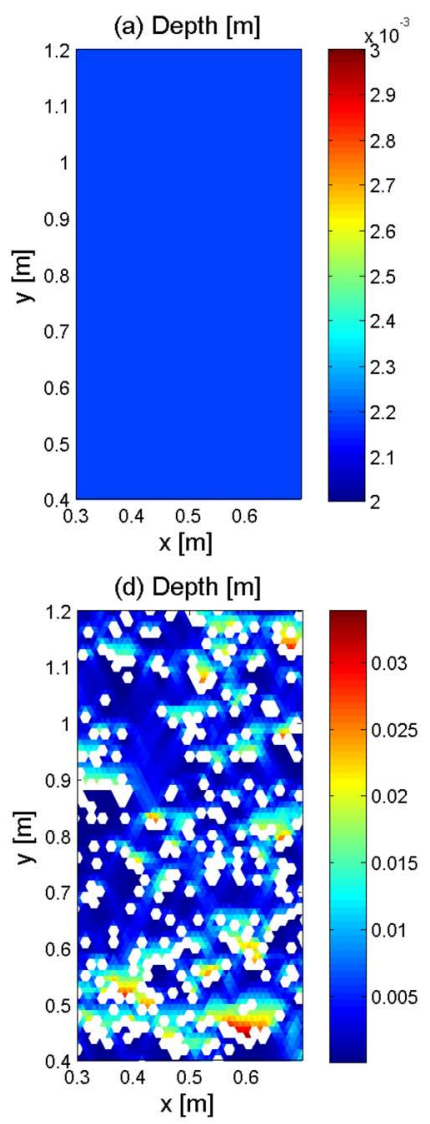

(b) Velocity $[\mathrm{m} / \mathrm{s}]$

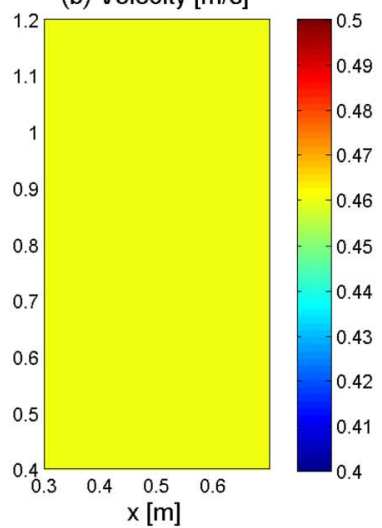

(e) Velocity $[\mathrm{m} / \mathrm{s}]$

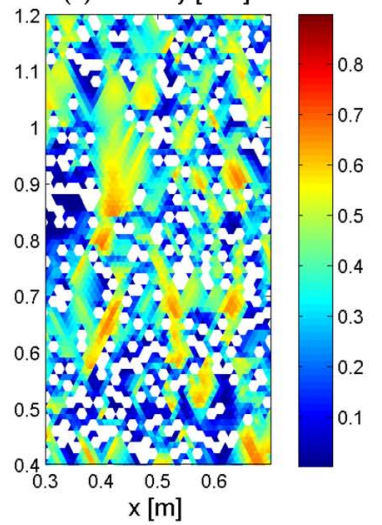

(c) Friction slope $[-]$

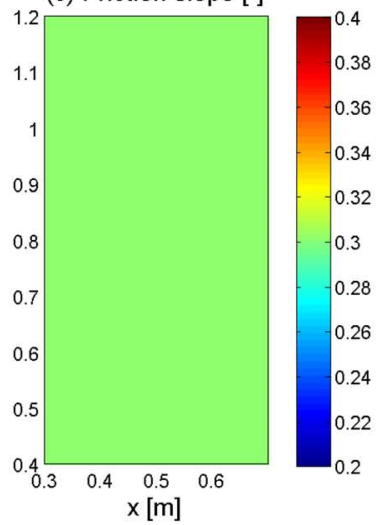

(f) Friction slope [-]

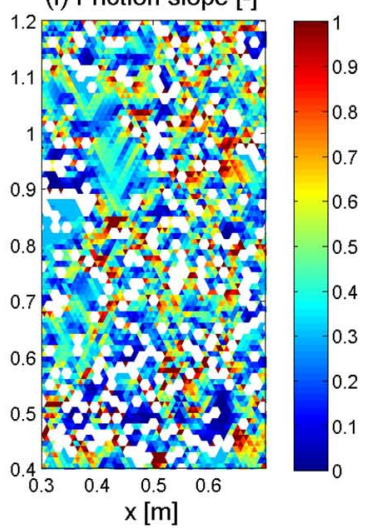

Figure 2. An illustration of the spatial distribution of flow variables at steady state for the case of domain slope of 0.3 and $Q=0.001 \mathrm{~m}^{3} \mathrm{~s}^{-1}$. (a-c) Illustrations of the distributions for a bare soil surface with $n_{b}=0.02 ;(\mathrm{d}-\mathrm{f})$ the distributions for the case of vegetation with the stem cover fraction of $30 \%$ $\left(n_{b}=0.02\right)$. Figures $2 \mathrm{a}$ and $2 \mathrm{~d}$ illustrate the flow depth $[\mathrm{m}]$; Figures $2 \mathrm{~b}$ and $2 \mathrm{e}$ illustrate the velocity magnitude $\left[\mathrm{m} \mathrm{s}^{-1}\right]$; and Figures $2 \mathrm{c}$ and $2 \mathrm{f}$ the friction slope [-]. The white color refers to vegetation stems; hydraulic variables are not simulated within these areas due to the imposed boundary condition of an impermeable, rigid, infinitely long wall.

with the results of the analytical steady uniform equation for the "turbulent rough flow", one of the four principal types of overland flow [Julien and Simons, 1985]. Specifically, Manning's $n_{b}$ of 0.02 corresponds to a roughness height of $\mathrm{mm}$ to $\mathrm{cm}$ scale (the mean diameter of sediment). This roughness height is much larger than the thickness of the boundary sublayer, $11.6 \mu / \rho \sqrt{g h S_{f}}$, and equal to $0.000144 \mathrm{~m}$, which indicates that the flow regime of this case is "turbulent rough". Furthermore, the effects of inertia and pressure terms are minimized and the bottom friction is balanced by the gravitational force. The friction slope under these conditions is thus almost the same as the plane slope, which is equal to 0.3 .

[23] If the flow occurs within a region with many protruding obstacles (i.e., impermeable, rigid stems of vegetation), the flow is faster between stems and retarded behind them. The flow depth and velocity vary appreciably over short distances (Figure 2, bottom). The "spots" of white color in Figure 2 (bottom) represent stem cells of vegetation and signify the imposed no-flow condition. The features of converging, accelerating currents between stems, and the formation of backwater upstream of the stems are well illustrated in Figure 2.
[24] The friction slope $S_{f}$, a key variable for estimating the roughness coefficient, is further investigated in terms of its relation to flow variables in the vegetated case. A qualitative interpretation of Figure 2 indicates that backwater regions have relatively larger depths, lower velocities, and smaller friction slopes, while the converging areas have higher velocities and friction slopes. In order to verify the general applicability of such statements, three distinct intervals of $S_{f}$ magnitude are considered: small $\left(S_{f}<0.233\right)$, medium $\left(0.233 \leq S_{f}<0.548\right)$, and high $\left(S_{f} \geq 0.548\right)$. The two critical values, i.e., 0.233 and 0.548 , represent the first and the fourth quartiles of the $S_{f}$ spatial variability. This implies that half of the $S_{f}$ magnitudes fall within the medium interval, while $25 \%$ of magnitudes fall within the intervals corresponding to small and high $S_{f}$. Statistical metrics, such as the means of $h, V$, and $S_{f}$ and their mutual correlation coefficients, are calculated for the entire domain (the cases of $V_{f}=0$ and $V_{f}=0.3$ ), and the three subintervals of $S_{f}$ (the case of $V_{f}=0.3$ ). The results are shown in Table 1 .

[25] The areas of the domain with locally small values of $S_{f}$ are in good accordance with the above conceptual partition. For example, backwater regions have larger flow 
Table 1. Mean Values and the Correlation Coefficients for the Entire Domain for the Cases of Both $V_{f}=0$ and $V_{f}=0.3^{\mathrm{a}}$

\begin{tabular}{lccccc}
\hline & & \multicolumn{4}{c}{$V_{f}=0.3$} \\
\cline { 3 - 6 } & $V_{f}=0$, & \multicolumn{4}{c}{$0.233 \leq S_{f}$} \\
& All $S_{f}$ & All $S_{f}$ & $S_{f}<0.233$ & $<0.548$ & $S_{f} \geq 0.548$ \\
\hline Mean $(h)$ & 0.0022 & 0.0055 & 0.0067 & 0.0044 & 0.0064 \\
Mean $(V)$ & 0.4602 & 0.3293 & 0.2463 & 0.3383 & 0.3942 \\
$\operatorname{Mean}\left(S_{f}\right)$ & 0.3000 & 0.4174 & 0.1325 & 0.3769 & 0.7830 \\
$\operatorname{Corr}\left(S_{f}, h\right)$ & - & 0.0821 & -0.2942 & 0.0582 & 0.3691 \\
$\operatorname{Corr}\left(S_{f}, V\right)$ & - & 0.2969 & 0.4038 & 0.1941 & -0.0639 \\
\hline
\end{tabular}

${ }^{\mathrm{a}}$ Only a subset of cases with small, medium, and high friction slopes were selected for the case of $V_{f}=0.3$. (Corr $=$ Correlation).

depths and smaller velocities, as compared to the mean conditions in the flow domain. However, using the values of $h, V$, and $S_{f}$ (corresponding to the interval of small $S_{f}$ values), the correlation coefficient between $h$ and $S_{f}$ is -0.294 , while between $V$ and $S_{f}$, it is 0.404 . Such a correlation is not sufficiently high to allow any general conclusion.

[26] The flow areas with high $S_{f}$ correspond to flow convergence and generally exhibit high-flow velocities. The mean velocity for such areas is $0.3942 \mathrm{~m} \mathrm{~s}^{-1}$, which is about $20 \%$ larger than the mean velocity for the entire domain $\left(0.3293 \mathrm{~m} \mathrm{~s}^{-1}\right)$. A conceptual dependence between the state of flow and $S_{f}$ is that flow retardation behind obstacles makes $S_{f}$ smaller, while flow acceleration in constricted areas between obstacles makes it larger, as compared to the case with a bare plane. For all domains, there is no statistically significant correlation of $S_{f}$ with the variables of $h$ and $F r$ (e.g., correlation coefficients between $S_{f}$ and $h$ or $F r$ are 0.082 and 0.14 ), while weak correlation with the variables of $V$ and $R e$ (e.g., correlation coefficients between $S_{f}$ and $V$ or $R e$ are 0.29 and 0.37 ) for vegetated hillslopes. These weak correlations make the generalization or prediction of the degree of high variability of $S_{f}$ at any internal point difficult and unfeasible. Therefore, the variability should be numerically modeled with a relevant detail in estimating roughness coefficients for problems in which the value of $S_{f}$ is necessarily needed for computations and plays a crucial role.

\subsection{Results for the Method of Equivalent Roughness Surface}

[27] Hydrographs at the downstream boundary of the domain were obtained for 324 simulations (as summarized in Table 2). They represent all possible permutations among 6 vegetation covers, 6 bed slopes, 3 base Manning coeffi-

Table 2. A Summary of the Simulation Cases ${ }^{\mathrm{a}}$

\begin{tabular}{ccccc}
\hline $\begin{array}{c}\text { Vegetation Cover } \\
\text { Fraction }\end{array}$ & $\begin{array}{c}\text { Domain } \\
\text { Slope }\end{array}$ & $\begin{array}{c}\text { Manning } \\
\text { Coefficient }\end{array}$ & $\begin{array}{c}\text { Inflow } \\
\text { Rate }\left(\mathrm{m}^{3} \mathrm{~s}^{-1}\right)\end{array}$ & $\begin{array}{c}\text { Rainfall } \\
\left(\mathrm{mm} \mathrm{h}^{-1}\right)\end{array}$ \\
\hline 0 & 0.1 & 0.02 & 0.0001 & 10 \\
0.05 & 0.3 & 0.03 & 0.0005 & \\
0.1 & 0.5 & 0.04 & 0.001 & \\
0.2 & 0.7 & & & \\
0.3 & 0.9 & & & \\
0.5 & 1.1 & & & \\
\hline
\end{tabular}

${ }^{\mathrm{a} E a c h}$ characteristic was permutated with all other variables. The total number of simulations is 324 . cients, and 3 upstream boundary inflow rates. Figure 3 shows 18 different hydrographs for fixed $S$ and $n_{b}$. Since overall trends shown in Figure 3 look similar to the trends in the other 17 plots (not shown) with different $S$ and $n_{b}$, only one plot (Figure 3 ) out of 18 obtained plots is illustrated. The figure shows the hydrographs for six different values of $V_{f}$ and three values of $Q$. The flow series with the same peak discharge correspond to the cases with the same $Q$; the series with larger times of concentration correspond to the cases with higher $V_{f}$ values. Based on these simulation results, it can be concluded that as $n_{b}$ and $V_{f}$ increase, and $Q$ and $S$ decrease, flow retardation becomes more pronounced, which results in higher values of $t_{c}$.

[28] In order to obtain a relationship between $t_{c}$ and $n$ for cases without vegetation, 144 additional simulations were carried out. These are summarized in Table 3. Hydrographs for the cases of $S=10 \%$ are shown in Figure 4, which includes 33 time series corresponding to 11 different $n$ and 3 different $Q$ values. It is evident that the flow is delayed and peaks occur later as the bed surface becomes rougher. The objective of these additional simulations was to develop relationships between $t_{c}$ and $n$ for exactly the same plane slopes and flow rates as those used in the scenarios with vegetation cover. For example, Figure 5 shows the computed (using the criteria of equation (1)) $t_{c}$ 's for two bed slopes $(10 \%$ and $110 \%)$ and different inflow rates. These relationships exhibit a positive, nonlinear dependence of $t_{c}$ on $n$. Once $t_{c}$ is obtained for any given case with vegetation cover, an equivalent $n_{t}$ can be estimated from the $t_{c}-n$ relationships obtained for bare soil plane, such as those illustrated in Figure 5.

\subsection{Results for the Method of Equivalent Friction Slope}

[29] The method of Equivalent Friction Slope averages spatially distributed flow depths and friction slopes and the upscaled, domain-representative Manning coefficient is calculated using equation (6). In order to investigate the difference between the upscaled coefficients obtained with the two methods, i.e., the Equivalent Roughness Surface and Equivalent Friction Slope methods, the estimates are compared in Figure 6. The figure indicates that both methods yield consistent estimates of $n_{t}$ with a coefficient of determination $R^{2}=0.973$. Values of $n_{t}$ obtained with the Equivalent Friction Slope method are used for further analysis.

[30] Figure 7 shows $n_{t}$ dependencies obtained with the Equivalent Friction Slope for all simulations summarized in Table 2. The figure and the table reflect variations of four independent variables: $V_{f}, S, Q$, and $n_{b}$. Figure 7 illustrates the general trends of effects on $n_{t}$ of all independent variables used in the study. For example, the effect of $V_{f}$ results in a positive dependence that is straightforward to discern. However, other effects, such as those of $Q$ or $n_{b}$, cannot be as clearly discerned in Figure 7. A discussion of the effects of these independent variables on $n_{t}$ is presented in section 5 .

\subsection{Predictive Equations for $\boldsymbol{n}_{\boldsymbol{t}}$}

[31] The values of $n_{t}$ obtained from the Equivalent Friction Slope are used to develop predictive equations for $n_{t}$. The relevant predictive variables and their corresponding 


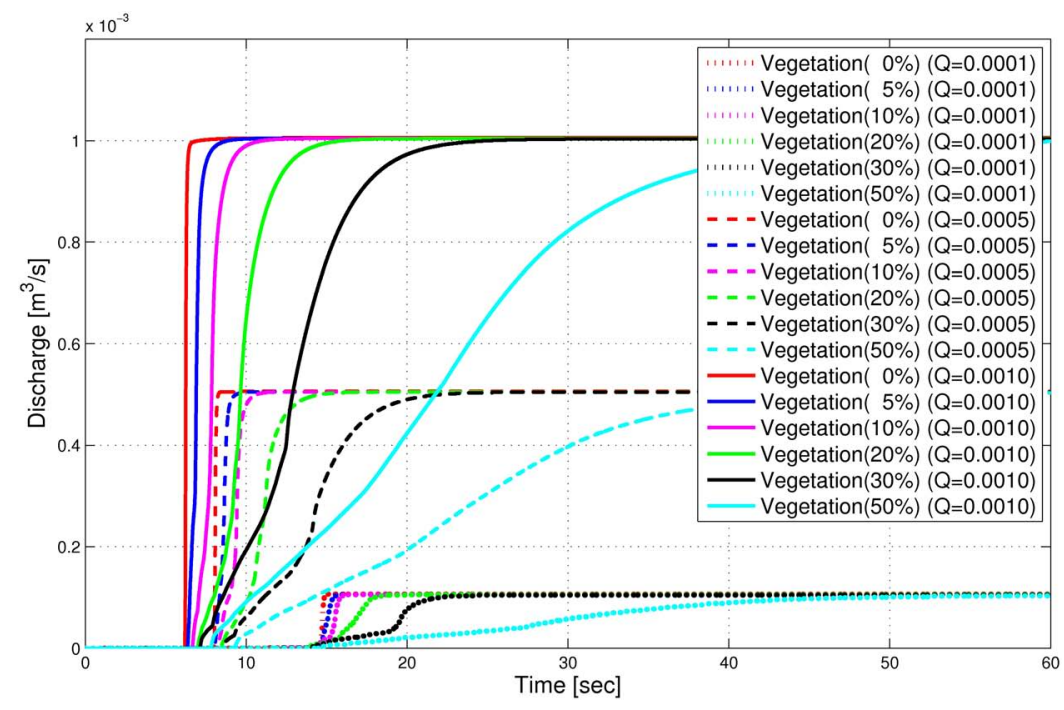

Figure 3. Simulated hydrographs for the cases with different vegetation covers (0 to $50 \%)$ for the plane slope of $10 \%$ and the base Manning's coefficient of 0.02 . The highest, middle, and lowest groups of hydrographs correspond to the cases of different inflow rates.

coefficients are determined by using a dimensional analysis and a multiple linear regression.

[32] Previous research has revealed that resistance to overland flow is influenced by many factors. Among them are the Reynolds number, the Froude number, flow depth, vegetation cover fraction, and the characteristics of roughness elements such as size, shape, spacing and pattern [Abrahams and Parsons, 1994]. The effect of the inflow rate on the resistance is taken into account by the Reynolds number. In this study, $n_{t}$ is assumed to be a function of the following variables:

$$
n_{t}=f\left(\rho, \mu, g, \bar{h}, \bar{V}, S, V_{f}, n_{b}\right) \text {, }
$$

where $\rho$ is the density of water $\left[\mathrm{ML}^{-3}\right] ; \mu$ is the dynamic viscosity of water $\left[\mathrm{ML}^{-1} \mathrm{~T}^{-1}\right] ; g$ is the acceleration due to gravity $\left[\mathrm{LT}^{-2}\right]$. The Buckingham $\Pi$-theorem is used to select $\rho, \bar{h}$, and $\bar{V}$ since these are repeating variables. The relevant dimensional parameters in the functional relation are

$$
n_{t}-n_{b}=f\left(\frac{\bar{h} \bar{V}}{v}, \frac{\bar{V}}{\sqrt{g \bar{h}}}, S, V_{f}\right)
$$

Table 3. A Summary of Simulation Cases Used in Comparisons With the Equivalent Roughness Surface Method ${ }^{\mathrm{a}}$

\begin{tabular}{ccccc}
\hline $\begin{array}{c}\text { Vegetation Cover } \\
\text { Fraction }\end{array}$ & $\begin{array}{c}\text { Domain } \\
\text { Slope }\end{array}$ & $\begin{array}{c}\text { Manning } \\
\text { Coefficient }\end{array}$ & $\begin{array}{c}\text { Inflow } \\
\text { Rate }\left(\mathrm{m}^{3} \mathrm{~s}^{-1}\right)\end{array}$ & $\begin{array}{c}\text { Rainfall } \\
\left(\mathrm{mm} \mathrm{h}^{-1}\right)\end{array}$ \\
\hline 0 & 0.1 & 0.05 & 0.0001 & 10 \\
& 0.3 & 0.06 & 0.0005 & \\
& 0.5 & 0.07 & 0.001 & \\
& 0.7 & 0.08 & & \\
& 0.9 & 0.09 & & \\
& 1.1 & 0.10 & & \\
& & 0.15 & & \\
& & 0.30 & & \\
& & & & \\
\end{tabular}

${ }^{\mathrm{a}}$ The total number of simulations is 144 .
Since this predictive equation has been previously developed in the form of a power function [Hu and Abrahams, 2006], equation (8) can be expressed in the following form:

$$
n_{t}-n_{b}=a\left(\frac{4 \bar{h} \bar{V}}{v}\right)^{b}\left(\frac{\bar{V}}{\sqrt{g \bar{h}}}\right)^{c}(S)^{d}\left(V_{f}\right)^{e} .
$$

The term on the left side of this equation expresses the effect of vegetation on the total resistance coefficient, i.e., it accounts for the contributions of both the form and wave resistances. The first term on the right side is multiplied by 4 to represent the Reynolds number and the second term represents the Froude number. The domain-averaged values of depth and velocity are used in the regression. The kinematic viscosity $v$ is used as a constant with the value of $10^{-6}\left[\mathrm{~m}^{2} \mathrm{~s}^{-1}\right]$, which corresponds to the temperature of water of about $20^{\circ} \mathrm{C}$. The evaluated coefficients $a, b, c, d$, and $e$ are $0.0264,0.2794,-0.9859,0.3060$, and 0.9591 , respectively, with $R^{2}=0.976$ of the log linear form. Note that this regression equation was developed for the cases used in the simulations that exhibit a wide range of possible scenarios of overland flow, i.e., $V_{f} \leq 0.5,0.1 \leq S \leq 1.1$, and $0.0001 \leq Q \leq 0.001$.

[33] As opposed to using all four dimensionless variables in equation (9), the consideration of only three dimensionless variables at a time can show the relative importance of the omitted variable in the variation of $n_{t}-n_{b}$. This procedure indicates that the exclusion of each variable $\operatorname{Re}, \mathrm{Fr}, \mathrm{S}$, and $V_{f}$ reduces the explained variation by $3.2,7.2,1.5$, and $35.7 \%$, respectively. Such a result implies that $V_{f}$ is the most dominant parameter in the determination of $n_{t}-n_{b}$. Thus, in an effort of simplification, if one chooses only $V_{f}$ to be present in the regression equation, the resulting form will be

$$
n_{t}-n_{b}=0.5172\left(V_{f}\right)^{1.7087}
$$




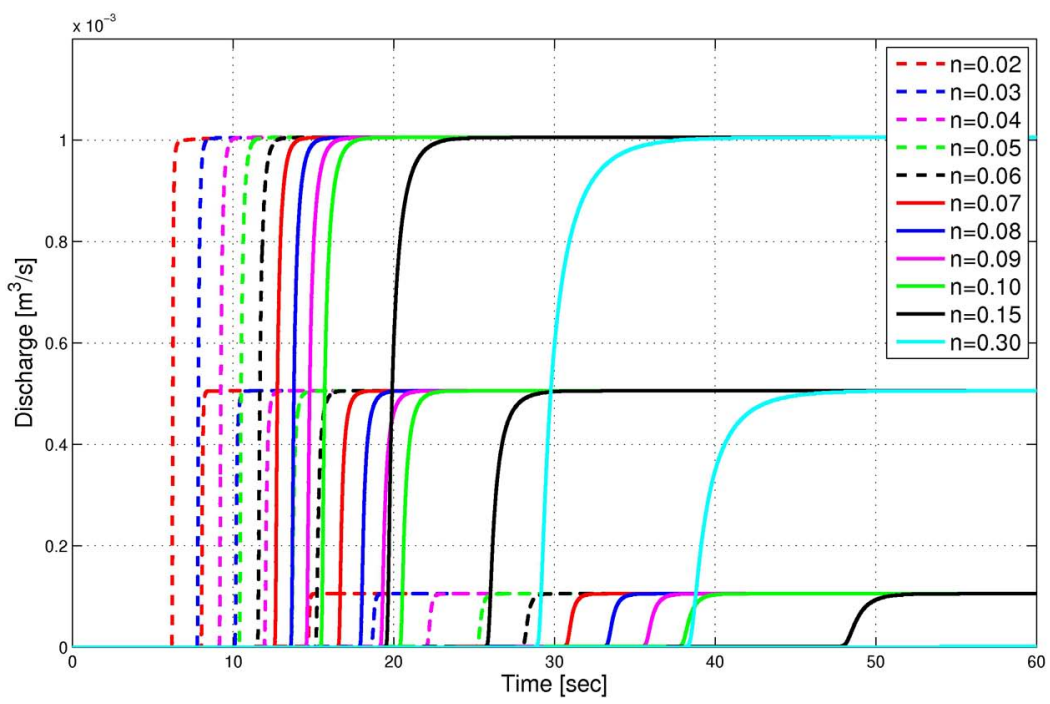

Figure 4. Simulated hydrographs for the cases without vegetation for the plane slope of $10 \%$. The highest, middle, and lowest groups correspond to the cases of different inflow rates of $0.001,0.0005$, and $0.0001 \mathrm{~m}^{3} \mathrm{~s}^{-1}$, respectively.

with $R^{2}=0.873$ (for the $\log$ linear form), i.e., $\log \left(V_{f}\right)$ can account for about $87 \%$ variation in $\log \left(n_{t}-n_{b}\right)$. Alternatively, if the regression equation is represented with an exponential function, the equation is

$$
n_{t}-n_{b}=0.0033 e^{8.8855 V_{f}}
$$

with $R^{2}=0.918$ (for the $\log$ linear form), which signifies a slightly better predictive power than equation (10).

[34] A number of scenarios (Table 4) for the highest inflow rate, $Q=0.01 \mathrm{~m}^{3} \mathrm{~s}^{-1}$, were introduced. The objective was to further investigate the effect of partially submerged obstacles on resistance for flow conditions that
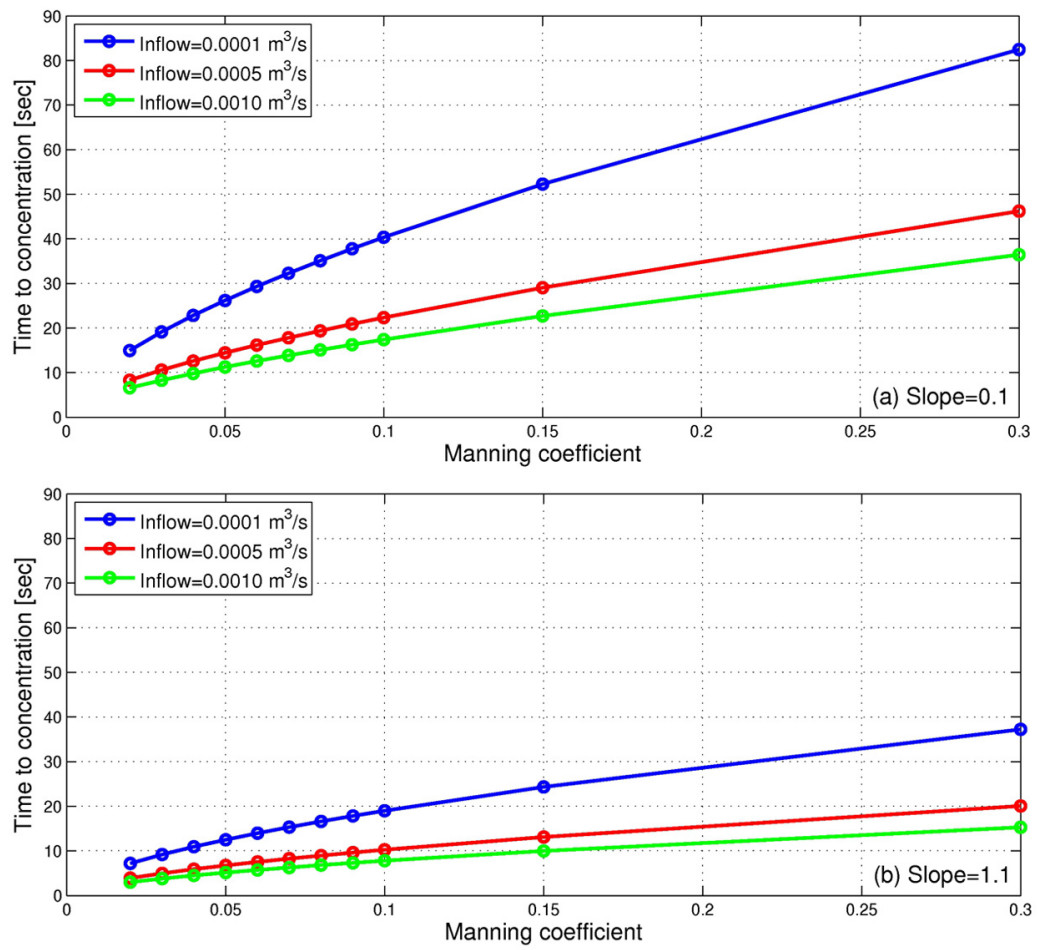

Figure 5. The time of concentration as a function of Manning's coefficient for the plane slopes of (a) $10 \%$ and (b) $110 \%$. The time of concentration was obtained using the Equivalent Roughness Surface method. 


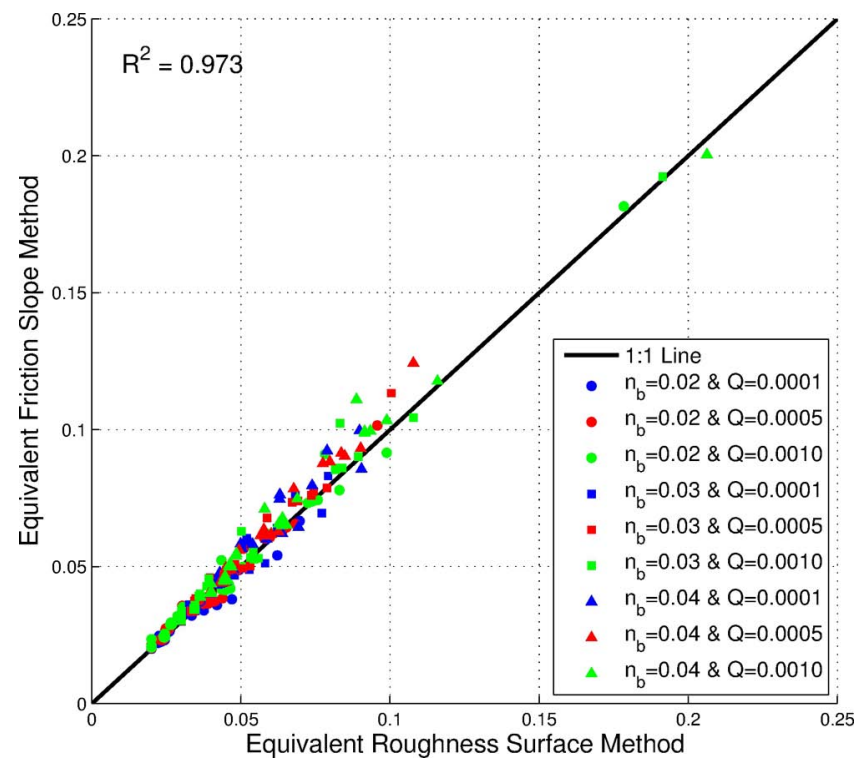

Figure 6. A comparison of the upscaled Manning's coefficients obtained with the hydrograph and dynamic wave analyses (section 4.3). The corresponding coefficient of determination is 0.973 . All simulation cases described in Table 2 are used.

represent an extreme range for natural hillslopes, i.e., highly infrequent. Another set of regression equations including simulation data for all of the cases summarized in Tables 2 and 4 are reported. Adding simulation data for $Q=0.01$ $\mathrm{m}^{3} \mathrm{~s}^{-1}$ to the regression set, equation (9) becomes

$$
n_{t}-n_{b}=0.0145\left(\frac{4 \bar{h} \bar{V}}{v}\right)^{0.3504}\left(\frac{\bar{V}}{\sqrt{g \bar{h}}}\right)^{-1.0293}(S)^{0.3238}\left(V_{f}\right)^{0.8925}
$$

with $R^{2}=0.969$ (for the log linear form) and has the range of applicability: $V_{f} \leq 0.5,0.1 \leq S \leq 1.1$, and $0.0001 \leq$ $Q \leq 0.01 \mathrm{~m}^{3 / s}$. Additionally, equation (11) becomes

$$
n_{t}-n_{b}=0.0039 e^{8.6799 V_{f}}
$$

with $R^{2}=0.831$ (for the $\log$ linear form). The regression equations (11) and (13) confirm that vegetation exerts a predominant effect on the roughness coefficient; therefore, the derived equations can be useful for estimating the degree of vegetation effects, if information on other significant variables is not readily available.

\subsection{Verification of the Regression Equation}

[35] Another set of simulation was carried out to verify the proposed regression equation for flow and domain conditions that were not used in the derivation of equations (9) and (12). The cases used in this verification test are described in Table 5. Specifically, they consist of 12 scenarios: $V_{f}$ is set to $0.25, n_{b}$ is equal to 0.025 , six different bed slopes range from 0.1 to 1.1 , and two inflow rates of 0.0003 and $0.0007 \mathrm{~m}^{3} \mathrm{~s}^{-1}$ are used. The values are within the ranges of applicability of the regression equation (section 4.4).
The upscaled Manning coefficients are calculated by using both the Equivalent Friction Slope and through the regression equations (9), (11), (12) and (13). The coefficients are consequently compared to verify the appropriateness of the derived equations, as shown in Figure 8. As seen, the differences between the coefficients obtained with the Equivalent Friction Slope and the coefficients calculated from equations (9) and (12) are fairly minor. However, there are nonnegligible deviations for the cases of small domain slope, when equations (11) and (13) are applied. This implies that for these cases, the inclusion of only $V_{f}$ is not sufficient to predict the upscaled roughness coefficients. Generally, one is cautioned against the use of equations (11) and (13) for situations when other variables become significant (a relevant discussion is also provided in section 5.1). On the other hand, the developed regression equations (9) and (12) that include all of the variables can become a useful tool for estimating roughness of vegetated surfaces, once the primary flow variables are known. However, note that equations (9) and (12) should be used with caution for variables that are beyond the range of hydraulic, geometric, and bed conditions described in Tables 2 and 4.

\subsection{Comparison of Results With Previous Studies}

[36] Data obtained in previous laboratory and field conditions are used in this study to provide a comprehensive validation set for the simulated effects of large-scale roughness elements. Data from five studies [Abrahams et al., 1986; Rauws, 1988; Gilley et al., 1992a; Bunte and Poesen, 1993; Hu and Abrahams, 2006] are summarized in Table 6.

[37] In order to ensure the most proper use of the data, and to represent the same flow situations in this study, a number of assumptions had to be made. First, the effective values of $V_{f}$ were recomputed for data reported in Bunte and Poesen [1993] and Abrahams et al. [1986] using auxiliary information reported in these studies. Specifically, in the former study, rock fragments, regardless of submerged conditions, were reported to range from 0 to $99 \%$ but some of the rocks were submerged by the flow, and thus the fragments did not contribute to $V_{f}$. This study specified the effective widths by considering only portions of protruding rocks; thus, we used the fraction of protruding rocks to obtain an effective fraction of $V_{f}$, which resulted in the $V_{f}$ range of $0-17 \%$. These values of $V_{f}$ are used for computation with the regression equation (12) and the results are shown in Figure 9. The uncertainty bounds are also shown, which indicate $10 \%$ of variability for the used $V_{f}$.

[38] Further, Abrahams et al. [1986] did not provide any detailed information on submerged gravel fractions by specifying only the fractions greater than $2 \mathrm{~mm}$. Therefore, an assumption was made that only half of the gravel fraction in Abrahams et al. [1986] could be considered as large elements (i.e., partially submerged condition). The determination of the effective $V_{f}$ was done through a summation of fraction for the two types of partially submerged elements: the reported vegetation fraction and half of the total gravel fraction. As a result, $V_{f}$ changed from the originally reported range of $56.5-88.2 \%$ to $30.6-54.1 \%$. Choosing the $50 \%$ ratio in order to get an effective $V_{f}$ is an unavoidable assumption and thus it influences the computation of the resistance coefficient. The sensitivity of estimates to this ratio 

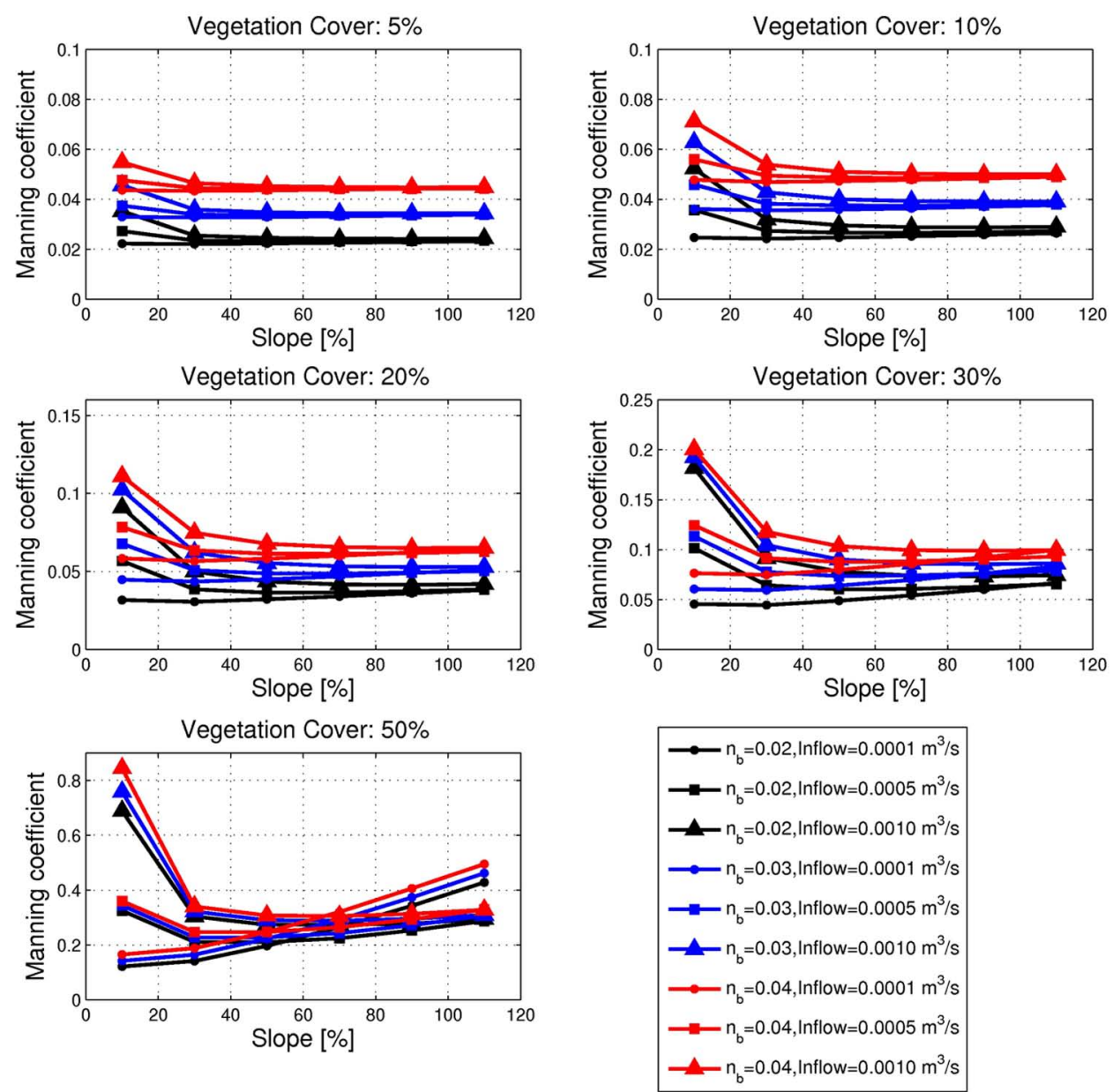

Figure 7. Upscaled Manning's coefficient values $\left(n_{t}\right)$ obtained with the equivalent friction slope method for different vegetation fractions, slopes, inflow rates, and base Manning coefficients corresponding to the cases summarized in Table 2. Among the total 324 scenarios, the results of cases with nonzero vegetation cover (270 scenarios in total) are shown.

is shown in the left plot of Figure 9: the black dots correspond to the ratio of $50 \%$, while the lower and upper bounds correspond to the ratios of 40 and $60 \%$, respectively. It is found that the effective rock ratio between $30 \%$ and $60 \%$ shows a reasonable match with the predicted values with limited deviations from the one-to-one regression line.

[39] Further, Gilley et al. [1992a] specified flow depths that were larger than the dimension of the gravel material;

Table 4. A Summary of Simulation Cases With High Inflow Rates $^{\mathrm{a}}$

\begin{tabular}{ccccc}
\hline $\begin{array}{c}\text { Vegetation Cover } \\
\text { Fraction }\end{array}$ & $\begin{array}{c}\text { Domain } \\
\text { Slope }\end{array}$ & $\begin{array}{c}\text { Manning's } \\
\text { Coefficient }\end{array}$ & $\begin{array}{c}\text { Inflow } \\
\text { Rate }\left(\mathrm{m}^{3} \mathrm{~s}^{-1}\right)\end{array}$ & $\begin{array}{c}\text { Rainfall } \\
\left(\mathrm{mm} \mathrm{h}^{-1}\right)\end{array}$ \\
\hline 0.05 & 0.1 & 0.04 & 0.01 & 10 \\
0.1 & 0.3 & & & \\
0.2 & 0.5 & & & \\
0.3 & 0.7 & & & \\
0.5 & 0.9 & & & \\
& 1.1 & & & \\
\hline
\end{tabular}

\footnotetext{
${ }^{\mathrm{a}}$ The total number of simulations is 30 .
}

consequently, 36 data points for the gravel bed and 20 data points for the cobble bed are excluded to avoid the submerged condition.

[40] In the study by Rauws [1988], the depth range of 0.5 to $1.5 \mathrm{~mm}$ for the subexperiment performed over the sand bed has a similar order of magnitude as the dimensions of the microscale sand bed $(1.18 \mathrm{~mm})$. In conditions of shallow flow over the sand bed, the effect of the surface resistance induced by the sand bed may be much larger than that of the form/wave resistances induced by the macroscale roughness (only $3.5 \%$ of $V_{f}$ ), and thus data of the sand bed experiment are also excluded from this analysis.

[41] The objective of this study is to investigate the effects of large-scale elements on the total resistance to flow. One way to carry out an analysis is to explore the fraction of the total resistance $\left(n_{t}\right)$ in reference to the resistance caused by small-scale elements, i.e., with respect to the surface resistance $n_{b}$. The left plot in Figure 9 illustrates a comparison of $n_{t}-n_{b}$ computed from the regression equation (12) and obtained from the reported data. It should be noted that in all of the experimental studies, the value of $n_{t}$ was given, but the value of $n_{b}$ was not provided in most studies, except for the work of Hu and Abrahams [2006]. 
Table 5. A Summary of Simulation Cases Used for the Verification of the Regression Equation ${ }^{\text {a }}$

\begin{tabular}{ccccc}
\hline $\begin{array}{c}\text { Vegetation Cover } \\
\text { Fraction }\end{array}$ & $\begin{array}{c}\text { Domain } \\
\text { Slope }\end{array}$ & $\begin{array}{c}\text { Manning's } \\
\text { Coefficient }\end{array}$ & $\begin{array}{c}\text { Inflow } \\
\text { Rate }\left(\mathrm{m}^{3} \mathrm{~s}^{-1}\right)\end{array}$ & $\begin{array}{c}\text { Rainfall } \\
\left(\mathrm{mm} \mathrm{h}^{-1}\right)\end{array}$ \\
\hline 0.25 & 0.1 & 0.025 & 0.0003 & 10 \\
& 0.3 & & 0.0007 & \\
& 0.5 & & & \\
& 0.7 & & & \\
0.9 & & & \\
& 1.1 & & & \\
\hline
\end{tabular}

${ }^{\mathrm{a}}$ The total number of simulations is 12 .

Thus, the surface resistance was derived based on auxiliary information provided for the small-scale roughness elements. In order to derive reasonable approximations, the Strickler formula [Chow, 1959] $n_{b}=0.041 D_{r}^{1 / 6}$ is used, where $D_{r}$ is the diameter of roughness elements in meters. We assumed the diameter of microscale elements: $500 \mu \mathrm{m}$ for loam in Abrahams et al. [1986] and $16 \mu \mathrm{m}$ for fiberglass in Gilley et al. [1992a]. We further found that the choice of the size of roughness elements does not influence the determination of $n_{b}$ appreciably. Note that even though several assumptions are made in the predicted $n_{t}-n_{b}$, the overall deviations in this plot are relatively minor $\left(R^{2}=0.898\right)$.

[42] A comparison of data points computed based on the results of this study with the estimates of the prognostic equation proposed by Hu and Abrahams [2006] is also presented. Specifically, these authors computed flow resistance from their experimental data and proposed a wave resistance $\left(f_{w}\right)$ formula for a fixed or mobile bed. The experiments were performed on a flume that had the following characteristics: $0.5 \mathrm{~m}$ wide, $4.9 \mathrm{~m}$ long, slope of 0.114 , covered with cylinders with the diameters of 0.02 or 0.031 $\mathrm{m}$ (served as large-scale roughness elements). The concentrations of cylinders ranged from 2 to $24 \%$, and flows ranged from 0.000185 to $0.0034 \mathrm{~m}^{3} \mathrm{~s}^{-1}$. Hu and Abrahams [2006] first calculated the total roughness $\left(f_{t}\right)$, the surface roughness $\left(f_{s}\right)$, and the form roughness $\left(f_{f}\right)$; they subsequently obtained $f_{w}$ by subtracting $f_{s}$ and $f_{f}$ from $f_{t}$. They presented a regression equation for a fixed bed as follows

$$
f_{w}=79.38\left(\frac{\bar{h}}{D_{r}}\right)^{0.25} F^{-0.5} R_{r}^{-0.33} V_{f}
$$

where $R_{r}$ is the roughness Reynolds number, $R_{r}=V D_{r} / v$.

[43] Using the flow variables obtained in this study, we can compute $f_{w}$. Specifically, since the effects of resistance due to rainfall and mobile bed on the total resistance are neglected, the latter can be divided into three components assumed to be additive. Therefore, $f_{w}$ is calculated with the following equation:

$$
f_{w}=f_{t}-f_{s}-f_{f}
$$

where the above three components on the right side of the equation are obtained from hydraulic results based on the numerical simulations: $f_{t}=8 g \overline{h S_{f}} / \bar{V}^{2} ; f_{s}$ can be substituted with $f_{t}$ calculated for the case of a domain without vegetation; and $f_{f}$ is calculated by using the modified drag model [Lawrence, 2000] for the case of partial inundation:

$$
f_{f}=\frac{2 f_{v} C_{D} \boldsymbol{A}(\bar{h} / k)}{\left[1-f_{v} \boldsymbol{V}(\bar{h} / k)\right]^{3}},
$$

where $\boldsymbol{A}(\bar{h} / k)$ accounts for the change in the frontal area with inundation, $\boldsymbol{V}(\bar{h} / k)$. accounts for the occluded volume of the roughness elements, and $C_{D}$ is the drag coefficient equal to 1.2 , which is the value used by $H u$ and Abrahams [2006]. The above formulation was originally developed for roughness elements with a hemispheric shape. Thus, if we apply this for the elements with the hexagonal column shape used in this study, we obtain $\boldsymbol{A}(\bar{h} / k)=$ $2 D_{r} \bar{h} / A_{r}$ and $\boldsymbol{V}(\bar{h} / k)=1$. Then, equation (16) becomes:

$$
f_{f}=\frac{4 D_{r} V_{f} C_{D} \bar{h}}{A_{r}\left[1-V_{f}\right]^{3}},
$$

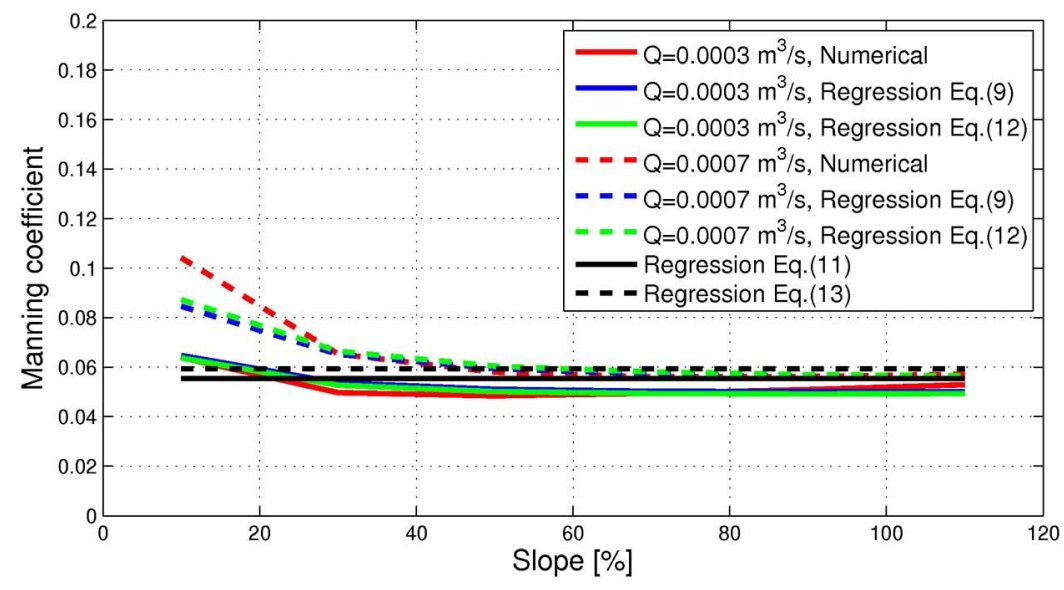

Figure 8. A comparison of the upscaled Manning coefficient obtained with the equivalent friction slope and the regression equations (9), (11), (12), and (13). Vegetation cover fraction of $25 \%$ and the base Manning's coefficient of 0.025 were used for this verification set. 
Table 6. A Summary of Experimental Studies Used in the Comparison ${ }^{\text {a }}$

\begin{tabular}{|c|c|c|c|c|c|c|c|}
\hline Publication & $\begin{array}{c}\text { Macroscale } \\
\text { Element }(\mathrm{cm})\end{array}$ & $\begin{array}{c}\text { Microscale } \\
\text { Element }(\mu \mathrm{m})\end{array}$ & $S(\%)$ & $R e$ & $F r$ & $V_{f}(\%)$ & $\begin{array}{l}\text { No. of Data Points } \\
\text { Reported/Used }\end{array}$ \\
\hline Abrahams et al. [1986] & $\begin{array}{c}\text { stones: } 0.68-4.13 \\
\text { vegetation }\end{array}$ & loam: 500 (assumed) & $9.2-68.7$ & $843-4378$ & $0.24-2.64$ & $30.6-54.1$ & 108/108 (field) \\
\hline Bunte and Poesen [1993] & pebble: $0.86-2.10$ & silica flour: 90 & 2.2 & $923-5615$ & $0.25-1.12$ & $0-17$ & $12 / 12$ (lab) \\
\hline Gilley et al. [1992a] & $\begin{array}{l}\text { gravel: } 2.54-3.81 \\
\text { cobble: } 12.7-25.4\end{array}$ & fiberglass: 16 (assumed) & 1.35 & $500-14,889$ & $0.13-1.46$ & $4-32$ & $100 / 44$ (lab) \\
\hline Hu and Abrahams [2006] & cylinder: $2.0 \& 3.1$ & aluminum & 11.4 & $1397-28,380$ & $0.51-2.81$ & $2-24$ & 68/68 (lab) \\
\hline Rauws [1988] & hemisphere: 1.6 & $\begin{array}{l}\text { silica flour: } 240 \\
\text { sand: } 1180\end{array}$ & $1.7-20.8$ & $122-2988$ & $0.97-2.76$ & 3.5 & 204/102 (lab) \\
\hline
\end{tabular}

aNotation "lab" is used for data obtained in laboratory conditions; "field" is used to denote field studies.

where $A_{r}$ is the area of the roughness element with the hexagonal shape. In order to verify the simulated results, we compared $f_{w}$ computed from equation (15) (they axis in Figure $9 \mathrm{~b}$ ) with $f_{w}$ predicted from equation (14) using the characteristics of flow scenarios of this study (the $x$ axis in Figure 9b).

[44] As Figure 9b shows, the results of applying equation (15) for $V_{f} \leq 0.3$ and $0.1 \leq S \leq 0.3$ are fairly consistent with the results obtained with equation (14) $\left(R^{2}=0.90\right.$ in log-transformed units), while the results outside of these ranges are not, especially for the data with larger $S$ and $V_{f}=0.5$. This can be partially attributed to the fact that the predictive equation (14) was derived for the conditions of $0.002 \leq V_{f} \leq 0.24$ and $S=0.114$, while this numerical study used a much larger range of slope magnitudes and vegetation cover fractions. The plot exhibits two discernible characteristics: first, an increasing vegetation cover implies an increase in wave resistance (a straightforward and consistent conclusion following from equation (14)); second, the higher the domain slope, the higher the differences between the compared $f_{w}$ values. The effect of slope was not included in equation (14) developed by $H u$ and Abrahams [2006] because they used a fixed domain slope, but, in general, it should be accounted for in the computation of $f_{w}$.

\section{Discussion}

\subsection{Effects of Vegetation Cover Fraction}

[45] It is apparent from the simulation results that as $V_{f}$ increases, $n_{t}$ also grows. This statement is also supported by the high values of the determination coefficient resulting from the estimates obtained with equations (11) and (13). Since in general hillslope flows have relatively small discharges, (e.g., see Abrahams et al. [1986] for Walnut Gulch Experimental Watershed), the results in cases presented in Table 2 are used in the following analysis. Figure 10 shows 54 ensemble lines that correspond to 6 domain slopes, 3 inflow rates, and 3 bed roughness coefficients. If the mean and the standard deviation of these ensemble lines are computed, the absolute contributions of protruding vegetation stems to $n_{t}$ are as high as 0.0047 , $0.0098,0.0242,0.0563$, and 0.2787 for $5,10,20,30$, and $50 \%$ vegetation cover fractions, respectively (see also Table 7). The effect of $V_{f}$ is generally insignificant for vegetation covers less than $10 \%$ but becomes more pronounced for higher fractions. This observation is also consistent with the results of Hirsch [1996]. Furthermore, an increase in $n_{t}-n_{b}$ for $V_{f}$ less than $20 \%$ is well aligned with a thesis of Einstein and Banks [1950] and Cowan [1956] who proposed that an effect of isolated roughness elements without mutual interference should be additive; or, in other words, $n_{t}-n_{b}$ should assume a linear growth. Conversely, a nonlinear increase of $n_{t}-n_{b}$ in the interval of $V_{f}$ from 30 to $50 \%$ is also observed. It is argued that a large portion of roughness elements forms clumps of obstacles, where a mutual interference of individual stem effects can be observed. This leads to a relatively higher retardation of the flow, as compared to the case with nearly no interference for $V_{f}$ less than $20 \%$.

[46] The residuals computed as the difference between the ensemble lines and the predicted values from the regression equation (11) are calculated as the difference between the natural logarithms of $n_{t}-n_{b}$ obtained from equation (11) and from the Equivalent Friction Slope method. In the bottom plot of Figure 10, the mean of residuals at each $V_{f}$ is nearly zero and the standard deviation of the residuals (in units of natural log-transform) is nearly constant. This ensures that the regression equation (11) is a consistent estimator.

[47] Equations (11) and (13) are derived only by considering the effects of vegetation fraction. Regardless of what the values of the other variables are (e.g., $Q$ or $S$ ), the values of $n_{t}-n_{b}$ predicted with these equations are the same. Predictions may therefore contain large errors in cases where the effects of $Q$ and $S$ become significant, and thus a caution should be used in using these equations. In particular, cases with small $S$ or high $V_{f}$ exhibit large effects of $Q$ and $S$, respectively. These are addressed in section 5.2.

\subsection{Effects of Bed Slope}

[48] As Figure 7 shows, it is difficult to infer a unique trend of the resistance coefficient relative to changes in $S$ because $n_{t}$ may exhibit both negative and positive variations. The negative trend of $n_{t}$ with growing $S$ is characteristic for high-flow rates, while a positive trend of $n_{t}$ with increasing $S$ can be discerned at low-flow rates. These changes are relatively minor for the cases with small vegetation cover. A positive trend with the domain slope at lowflow rates also emerged in the experimental study by Hessel et al. [2003], who used a discharge of about $6.67 \times$ $10^{-5} \mathrm{~m}^{3} \mathrm{~s}^{-1}$. Their study used bed slopes less than $64 \%$, a relatively small inflow rate, and vegetation cover fractions smaller than $\sim 30 \%$. For a cropland area, they found an increase in Manning's coefficient with increasing slope.

[49] To further investigate possible trends, a set of simulation scenarios summarized in Table 4 were considered in addition to the cases described in Table 2. These included 

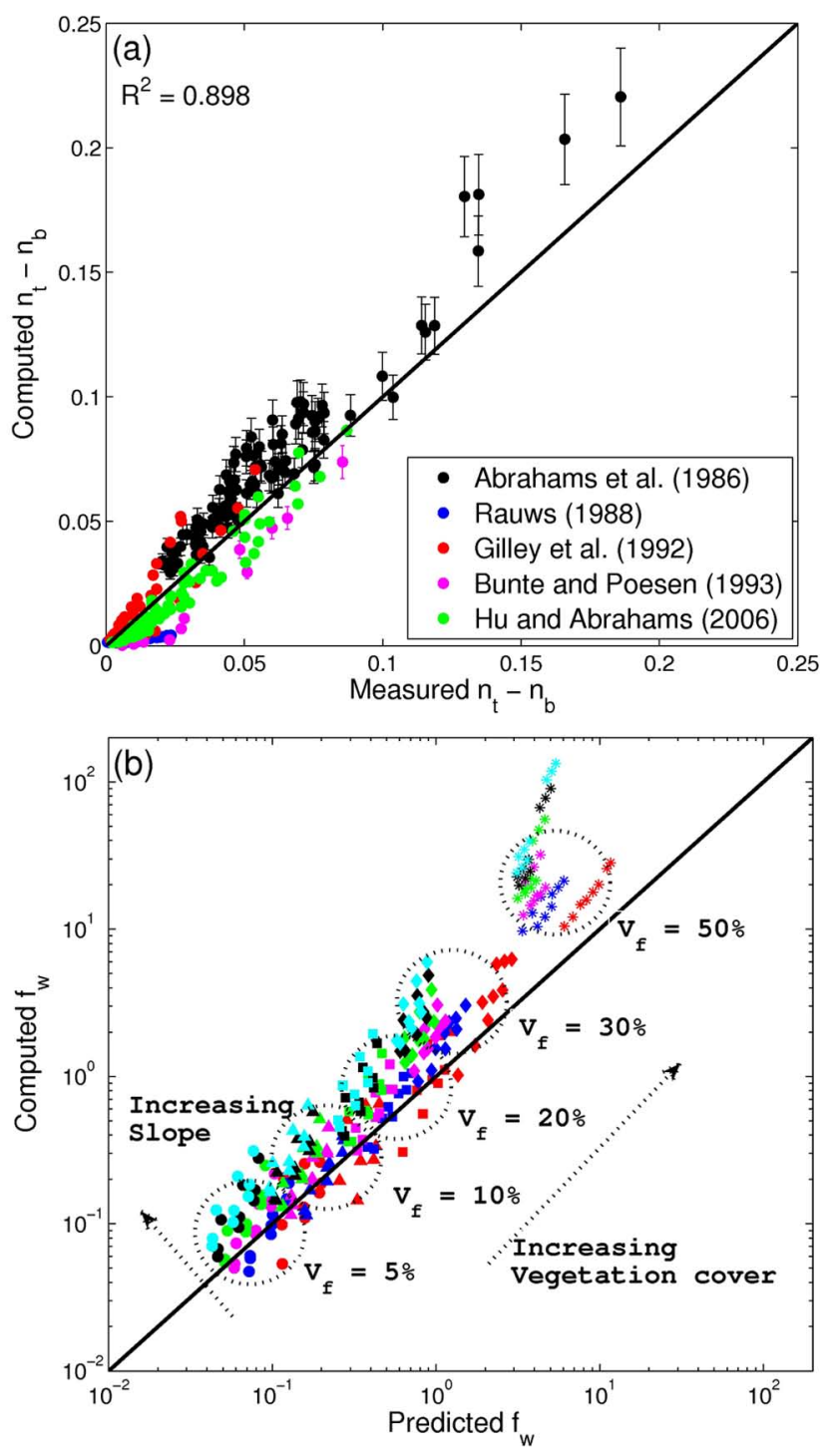

Figure 9. (a) A comparison of $n_{t}-n_{b}$ values computed from the regression equation (12) ( $y$ axis) and obtained from the measured data ( $x$ axis) reported in five different studies $\left(R^{2}=0.90\right)$. (b) A comparison of the computed $f_{w}$ from equation (15) and predicted $f_{w}$ from equation (14). In Figure $9 \mathrm{~b}$, the coefficient of determination $R^{2}=0.72$ in log-transformed units for all of the values; $R^{2}=0.90$ in $\log$-transformed units for data corresponding to $S=0.1$ and 0.3 . The circle, triangle, square, and diamond symbols represent the cases with $V_{f}=5,10,20,30$, and $50 \%$, respectively. The red, blue, magenta, green, black, and cyan symbols represent the cases with $\mathrm{S}=0.1,0.3,0.5,0.7,0.9$, and 1.1, respectively. All of the 270 scenarios (excluding the 54 scenarios with zero vegetation fraction) summarized in Table 2 were used.

extreme cases with a higher inflow rate of $0.01 \mathrm{~m}^{3} \mathrm{~s}^{-1}$. Flow rates reaching or exceeding such a magnitude are unlikely to occur in real-world hillslopes, except for most extreme hydrologic events. The four considered inflow rates, i.e., $0.0001,0.0005,0.001$, and $0.01 \mathrm{~m}^{3} \mathrm{~s}^{-1}$, therefore span the likeliest possible range and extend the analysis to "limiting" flow conditions. Similar to previous results in Figure 7, the set of simulation cases for $Q=0.01 \mathrm{~m}^{3} \mathrm{~s}^{-1}$ exhibit a decreasing trend of $n_{t}$ with growing slope (not shown).

[50] The effects of the difference in possible trends can be explained by using the Manning's equation. For a given inflow rate, the spatial variability of $n_{t}$ is influenced by both friction slope and depth:

$$
n_{t}=\bar{h}^{\frac{5}{3}} S_{f}^{\frac{1}{2}} / q
$$

If the plane slope is increased, the friction slope will also grow, and the flow depth will decrease. These two effects exert a conflicting impact on the determination of $n_{t}$ and thus are the reason of the two trends observed in the simulation results for changes in the bed slope. A specific trend (i.e., the growth or decay of $n_{t}$ with $S$ ) is observed depending on whether the contribution of one effect overwhelms the contribution of the other. Selecting $10 \%$ bed slope as a "reference" slope and deriving the ratio of $n_{t}$ at any slope with respect to $n_{t, 10 \%}$ at this reference slope yields an equation in a logarithmic form:

$$
\log \left(\frac{n_{t}}{n_{t, 10 \%}}\right)=\frac{5}{3} \log \left(\frac{\bar{h}}{\bar{h}_{10 \%}}\right)+\frac{1}{2} \log \left(\frac{\bar{S}_{f}}{\bar{S}_{f, 10 \%}}\right),
$$

which implies that $n_{t}$ varies according to its controlling variables $\bar{h}$ and $\overline{S_{f}}$. The three terms of equation (19) are shown in Figure 11 for three different vegetation cover fractions of 0,10 , and $30 \%$. For $V_{f}=0$, the effects of $\bar{h}$ and $\overline{S_{f}}$ are nearly identical in the absolute magnitude and thus $n_{t}$ is almost constant. However, for larger stem fractions (e.g., $V_{f}=0.3$ ), the gradient $\partial n_{t} / \partial S$ is less than zero for larger inflow rates and nearly always positive for the smallest flowrate. The latter effect is because the relative rate of increase of $\overline{S_{f}}$ with respect to $\bar{S}_{f, 10 \%}$ is higher than the rate of decrease of $\bar{h}$ with respect to $\bar{h}_{10 \%}$; the opposite holds true for the higher-flow rates. One can consequently infer that the gradient $\partial n_{t} / \partial S$ becomes zero or, equivalently, exhibits a local minimum, where the two effects are balanced.

[51] In order to address these trends mathematically and verify the condition of existence of a point of local minimum, the regression equation (12) including $R e$ and $F r$ is rewritten through the unit discharge and flow depth, as follows:

$$
n_{t}-n_{b}=9.6580(q)^{-0.6789}(\bar{h})^{1.544}(S)^{0.3238}\left(V_{f}\right)^{0.8925}
$$

Given constant $q$ and $V_{f}$, the derivative of $\partial n_{t} / \partial S$ is

$$
\begin{gathered}
\frac{\partial n_{t}}{\partial S}=9.658(q)^{-0.6789}\left(V_{f}\right)^{0.8925}(\bar{h}) 0.544(S)^{0.3238} \\
{\left[1.544 \frac{\partial \bar{h}}{\partial S}+0.3238 \frac{\bar{h}}{S}\right]}
\end{gathered}
$$

The first four terms in equation (21) are always positive. The gradient $\partial n_{t} / \partial S$ therefore depends on the sign of the expression in the brackets. To find a minimum point at 

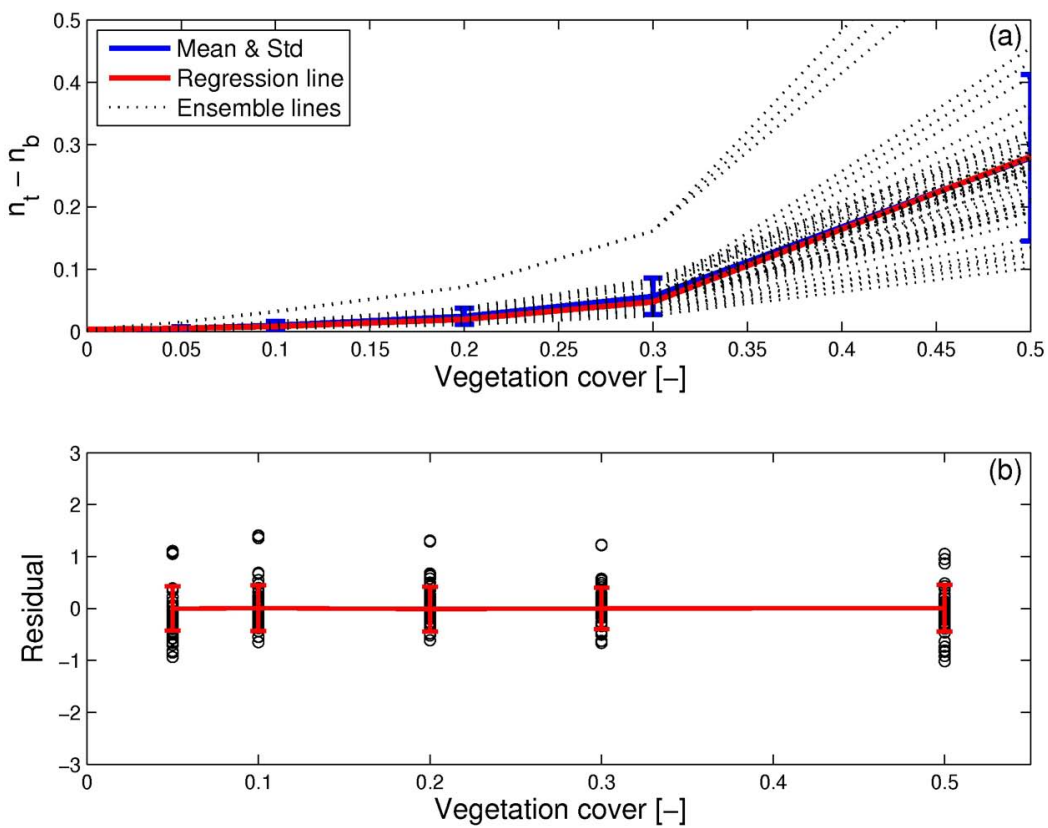

Figure 10. The effect of vegetation cover fraction on Manning's coefficient. (a) The dotted lines show the results of 54 simulation cases ( 3 inflow rates, 3 base Manning coefficients, and 6 domain slopes were permutated); the solid blue line illustrates the mean of simulations for a given $V_{f}$, while the vertical bars show the standard deviation; and the red line illustrates the regression line based on equation (11) with $R^{2}=0.918$ (log-transformed). (b) The regression residuals (circles), their mean values (red line), and the standard deviations (red vertical bars). The residuals are calculated as the difference between the natural logarithms of $n_{t}-n_{b}$ obtained from equation (11) and from the equivalent friction slope method.

which the sign of dependency of $n_{t}$ on slope is changed, the above equation is set to zero:

$$
\frac{\partial \bar{h}}{\partial S}+0.2097 \frac{\bar{h}}{S}=0
$$

from this one obtains:

$$
\bar{h} S^{0.2097}=\text { constant. }
$$

Because $\bar{h} / S$ is always positive, the variability of $n_{t}$ on $S$ is determined by the magnitude of $\partial \bar{h} / \partial S$. The expression in equation (22) shows that $n_{t}$ decreases only when the gradient of depth with respect to the bed slope $(\partial \bar{h} / \partial S)$ is large enough (absolute of negative value), as compared to the ratio of depth and bed slope $(\bar{h} / S)$; conversely, $n_{t}$ increases when $\partial \bar{h} / \partial S$ has only a relatively small negative value. If the integration constant is known, the trend of $n_{t}$ on $S$ can be explicitly determined from equation (23). Although the above equations are derived from an empirical regression equation, they indicate that the variability of $\bar{h}$ with respect to $S$ plays a key role in determining the shape of $n_{t}$ on $S$.

\subsection{Effects of Inflow Rate}

[52] Implications of the change of the flowrate are such that $n_{t}$ slightly increases with $Q$. An increase of the wetted projected area of vegetation stems with growing $Q$ can explain this phenomenon [Abrahams et al., 1986]. However, for all cases, this trend does not represent a statistically meaningful result since $Q$ is not highly correlated with $n_{t}$, and the standard deviation of the latter for each flowrate is high, as compared to its mean. The coefficient of determination, $R^{2}$ of the regression equation between $Q$ and $n_{t}$ is less than 0.1 regardless of the selected equation type, such as linear or log-transformed power, exponential, or logarithmic functions.

\begin{tabular}{|c|c|c|c|c|c|c|c|}
\hline$n_{b}$ & Statistics & $V_{f}=0$ & $V_{f}=0.05$ & $V_{f}=0.1$ & $V_{f}=0.2$ & $V_{f}=0.3$ & $V_{f}=0.5$ \\
\hline \multirow[t]{2}{*}{0.02} & Mean & 0.0006 & 0.0043 & 0.0090 & 0.0220 & 0.0526 & 0.2645 \\
\hline & SD & 0.0008 & 0.0030 & 0.0065 & 0.0138 & 0.0309 & 0.1236 \\
\hline \multirow[t]{2}{*}{0.03} & Mean & 0.0005 & 0.0047 & 0.0098 & 0.0241 & 0.0561 & 0.2780 \\
\hline & SD & 0.0009 & 0.0030 & 0.0063 & 0.0134 & 0.0299 & 0.1344 \\
\hline \multirow[t]{2}{*}{0.04} & Mean & 0.0005 & 0.0052 & 0.0108 & 0.0266 & 0.0601 & 0.2935 \\
\hline & SD & 0.0009 & 0.0026 & 0.0056 & 0.0124 & 0.0281 & 0.1481 \\
\hline \multirow[t]{2}{*}{ All } & Mean & 0.0005 & 0.0047 & 0.0098 & 0.0242 & 0.0563 & 0.2787 \\
\hline & SD & 0.0008 & 0.0028 & 0.0060 & 0.0131 & 0.0292 & 0.1337 \\
\hline
\end{tabular}

Table 7. Means and the Standard Deviations of the Difference Between the Upscaled and Base Manning's Coefficient $n_{t}-n_{b}{ }^{\mathrm{a}}$

\footnotetext{
${ }^{\mathrm{a}}$ Results for all simulations are presented. $(\mathrm{SD}=$ Standard deviation).
} 
(a)

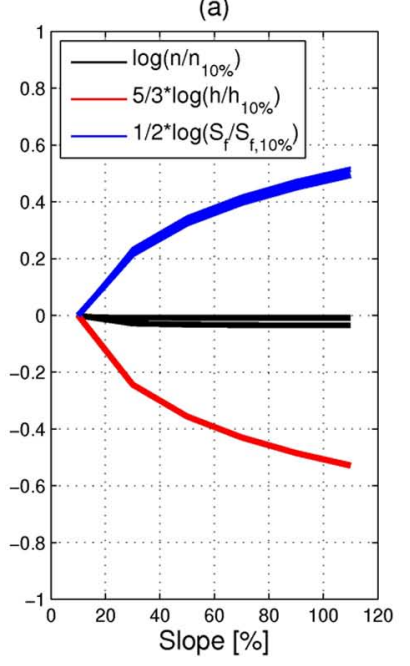

(b)

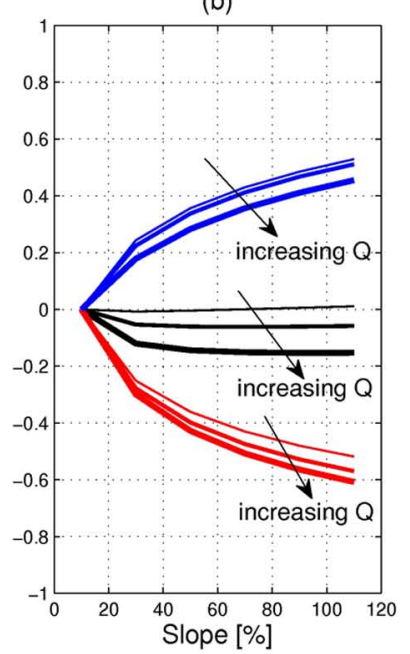

(c)

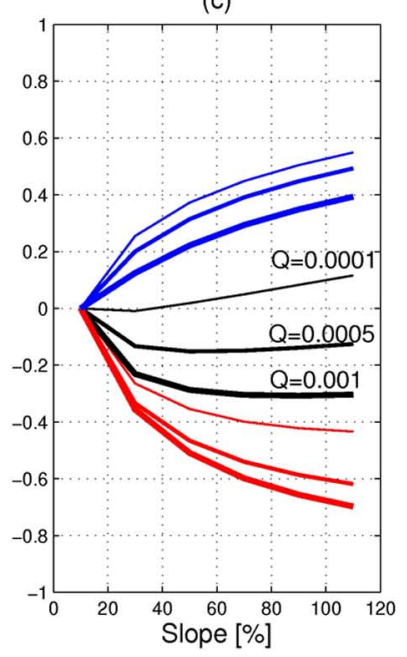

Figure 11. The log-ratio of $n, h$, and $S_{f}$ to their respective magnitudes at $10 \%$ bed slope. The thin, the medium, and the thick lines correspond to the inflow rates $Q$ of $0.0001,0.0005$ and $0.001 \mathrm{~m}^{3} \mathrm{~s}^{-1}$. Vegetation covers are (a) $0 \%$, (b) $10 \%$, and (c) $30 \%$.

[53] As seen in Figure 7, the effects of $Q$ on $n_{t}$ are conveyed in two ways: an increasing trend of $n_{t}$ with $Q$, when the domain slope is small, and a decreasing trend for a steeply sloped plane. This effect of $Q$ on $n_{t}$ can be addressed in a fashion similar to the one used in section 5.2. Given constant $S$ and $V_{f}$, the derivative of $\partial n_{t} / \partial q$ is

$$
\begin{gathered}
\frac{\partial n_{t}}{\partial q}=9.658(q)^{-0.6789}\left(V_{f}\right)^{0.8925}(\bar{h})^{0.544}(S)^{0.3238} \\
{\left[1.544 \frac{\partial \bar{h}}{\partial q}-0.6789 \frac{\bar{h}}{q}\right]}
\end{gathered}
$$

Since the first four terms in equation (24) are always positive, the gradient $\partial n_{t} / \partial q$ depends on the sign of the expression in the brackets:

$$
\frac{\partial \bar{h}}{\partial q}-0.4397 \frac{\bar{h}}{q}=0 .
$$

Since $\partial \bar{h} / \partial q$ is positive, $n_{t}$ can increase or decrease with $q$ depending on whether the gradient of depth with respect to inflow rate $(\partial \bar{h} / \partial q)$ is larger than their ratio $(\bar{h} / q)$. Given constant $S$ and $V_{f}$, the variability of $\bar{h}$ with respect to $q$ plays a key role in determining the shape of $n_{t}$ on $q$.

\subsection{Effects of Bed Surface Roughness Condition}

[54] When overland flow occurs in areas with emerging vegetation, characteristics of original soil, expressed here as the base Manning's resistance coefficient $n_{b}$, may also affect the domain-representative roughness coefficient $n_{t}$. Various conditions of the bed surface are represented with different values of $n_{b}$, e.g., a larger $n_{b}$ corresponds to a rougher condition of the bed. The effect of $n_{b}$ on $n_{t}$ is illustrated in Figure 12 in which $n_{t}-n_{b}$ is used as the variable for they axis. This difference can be also recognized as the net total contributions of the form and wave resistances, which need to be accounted for in the presence of obstacles.
Note that an analysis of the effect of $n_{b}$ should be carried by mutually comparing the sets of lines of different color: red $\left(n_{b}=0.04\right)$, black $\left(n_{b}=0.02\right)$, and blue $\left(n_{b}=0.03\right)$ lines (see Figure 12). The red lines are mostly above the black lines, which implies that the rougher the surface of the plane, the larger the effect of the form/wave resistances due to vegetation. As compared to the smoother bed corresponding to $n_{b}$ of 0.02 , the rougher bed with $n_{b}$ of 0.04 leads to increasing contributions of the form/wave resistances to $n_{t}$ by about $21,20,21,14,11 \%$ for the vegetation cover of 5 , $10,20,30,50 \%$, respectively (Table 7).

\subsection{Relationship Between Flow Depth or Velocity and the Manning Coefficient}

[55] Patterns of a relationship between the upscaled Manning's coefficient $n_{t}$ and main flow variables ( $h$ and $V$ ) are illustrated in Figure 13. For a fixed $S$ and $Q, n_{t}$ is positively related to $h$ and is negatively related to $V$. These relationships are consistent with the previous discussion of relationships between $n_{t}$ and independent variables and corroborate the results of studies by Fathi-Moghadam [2006].

\subsection{Validity of Performance Skill}

[56] Despite the simplified nature of the S-V equations and the implications of underlying assumptions, the results of this study are consistent with a broad range of data from five experimental studies. While some of the reported data required additional interpretations and thus resulted in a larger uncertainty, no assumptions were made when recent data by $H u$ and Abrahams [2006] were used (see section 4.6) and the obtained results showed an excellent skill. Furthermore, the reported simulation results confirmed a regression equation for the wave resistance proposed by $H u$ and Abrahams [2006] (see section 4.6) and relationships between resistance and depth/velocity proposed by FathiMoghadam [2006] (see section 5.5). One possible reason of why the application of the S-V equations has demonstrated such a good performance could be due to a relatively minor role that obstacle-induced eddies play in affecting larger-scale 

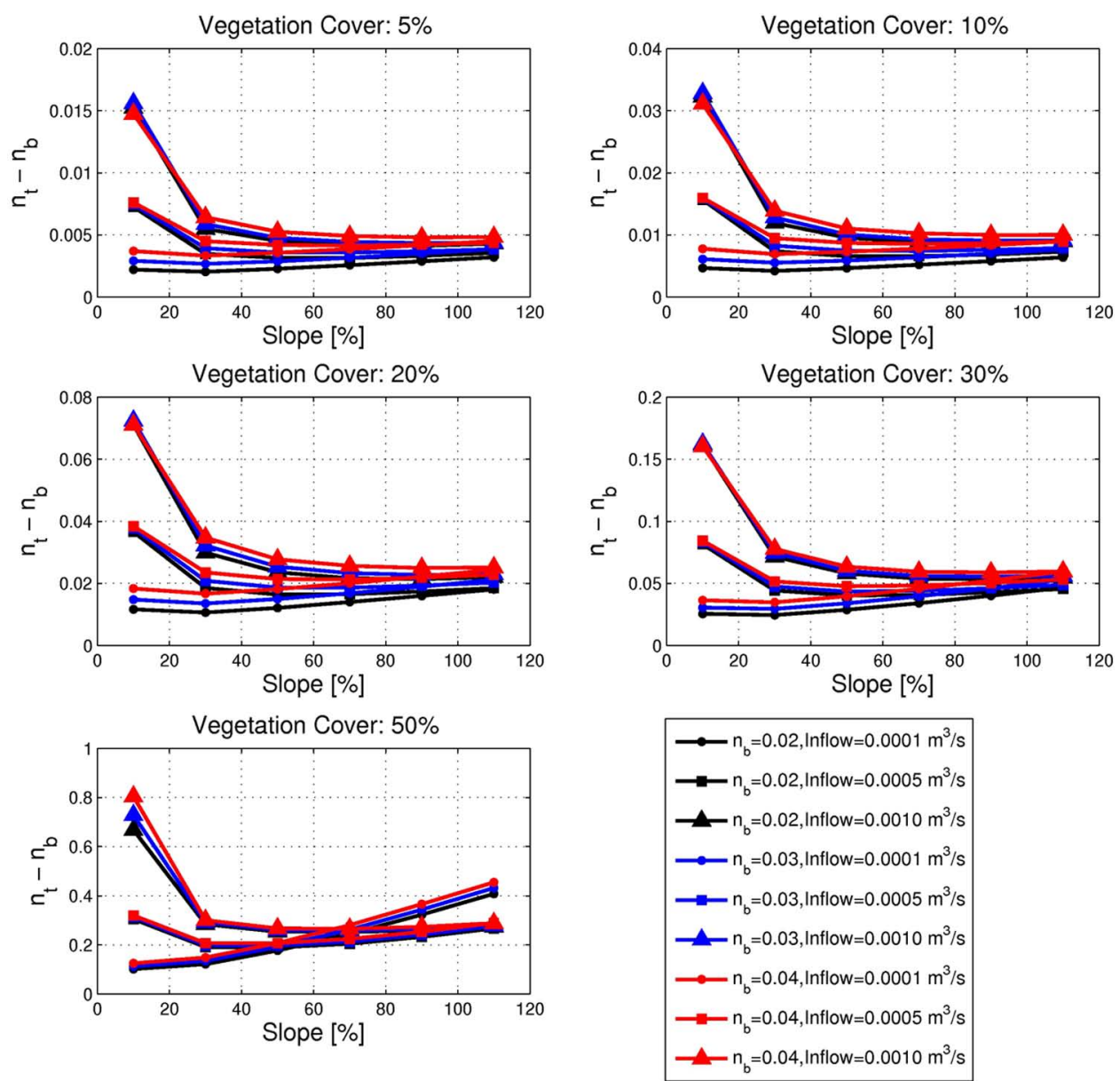

Figure 12. The effects of the base Manning's coefficient $n_{b}$ on upscaled $n_{t}$ for different vegetation fractions. The results were obtained using the equivalent friction slope method. Note that while Figure 7 illustrates the total resistance, this figure shows the sum of the form and wave resistances, which implies the net total contribution of resistances due to partially submerged vegetation to the total resistance.

characteristics of the flow. As Stoesser et al. [2010] illustrated, the time-averaged streamwise (horizontal) velocities resulting from their 3-D LES model show similar patterns to those obtained in this study: higher velocity between stems and smaller velocities behind stems. Although there can be no exact comparison between the two studies, one important inference from Stoesser et al. [2010] is that the size/region of wake behind a vegetation stem is relatively small as compared to the stem diameter. This indicates that a possible uncertainty region, due to inability to explicitly resolve eddies with the $\mathrm{S}-\mathrm{V}$ model, may be restricted to a single triangle cell behind any given stem represented in this study.

\section{Conclusions}

[57] Using high-resolution, hydrodynamic numerical simulation results performed at very fine space-time scales, two methods were developed to obtain the upscaled Manning coefficient, specifically, "the Equivalent Roughness Surface" (ERS) and "the Equivalent Friction Slope" (EFS) methods. The former approach assumes that the resistance of a rough plane bed without vegetation is equal to the resistance of a smooth plane covered with vegetation stems or other obstacles. The latter method obtains the upscaled resistance by using information on flow depth, velocity, and friction slope simulated at steady state in internal points of a domain. The values obtained with these two methods yield nearly identical estimates of $n_{t}$; the coefficient of determination of the relationship between them is $R^{2}=0.973$.

[58] The values of $n_{t}$ obtained in the simulation scenarios described in Tables 2 and 4 were used to develop a predictive equation. The relevant variables and their corresponding coefficients were determined by using the dimensional analysis and a multiple linear regression analysis. A general relation accounting for the effect of four independent variables (i.e., $S, Q, n_{b}$, and $V_{f}$ ) is given by equation (12), which is applicable to conditions with $V_{f} \leq 0.5,0.1 \leq S \leq 1.1$, and $0.0001 \leq Q \leq 0.01$.

[59] We compared $n_{t}-n_{b}$ computed from the general regression equation (12) with data reported in five different studies, as presented in Table 6. Although certain assumptions had to be made, so as to derive representative values of $n_{b}$ and $V_{f}$, the overall deviations were minor $\left(R^{2}=\right.$ 0.898). Also, the wave resistance coefficients obtained with the Equivalent Friction Slope method were compared with estimates from a predictive equation of $\mathrm{Hu}$ and Abrahams [2006]. We found that the estimates are quite consistent with the numerical results obtained in this study within the 

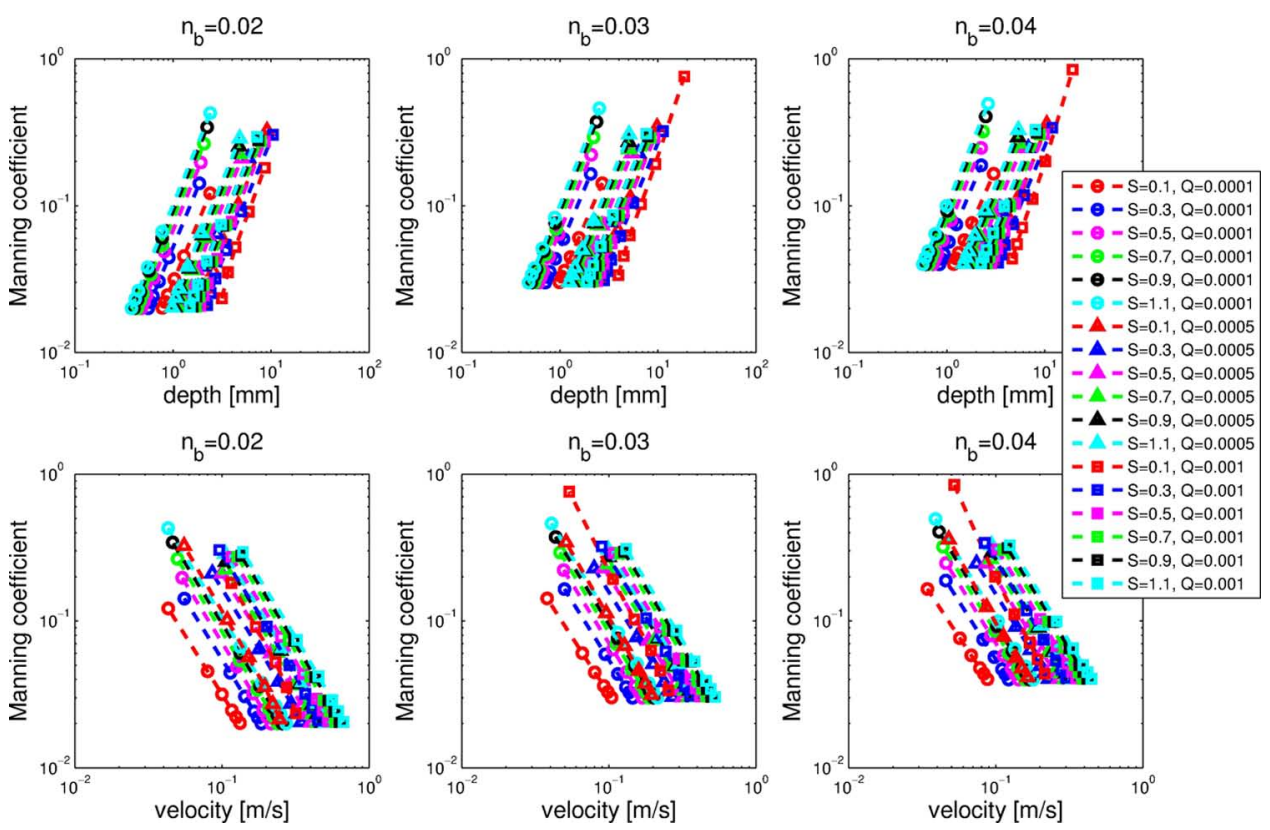

Figure 13. Upscaled Manning's coefficients $\left(n_{t}\right)$ shown with respect to average flow depth and velocity. The results were obtained using the equivalent friction slope method for different slopes, inflow rates, and base Manning coefficients corresponding to the cases summarized in Table 2. Six points in each line correspond to six vegetation fractions.

range of experimental conditions for which the equation of $\mathrm{Hu}$ and Abrahams [2006] was developed. Overall, it follows that the predictive equation derived in this study is well corroborated by reported experimental data and a previously developed formulation for wave resistance. Thus, this framework can become a suitable tool for predicting roughness coefficient for vegetated hillslopes.

[60] Furthermore, the effects of independent variables on $n_{t}$ were investigated. First, the effect of $V_{f}$ on $n_{t}$ is that as $V_{f}$ increases, $n_{t}$ also grows. This positive trend is represented by equation (11) and equation (13) with high values of the determination coefficient of the log-transform linear relationships. These equations can be useful in estimating the degree of vegetation effects on resistance, when other variables required by equations (9) or (12) are not available. However, they cannot be used in cases where effects of other independent variables become significant: for example, the effects of $Q$ are significant in cases with small $S$ values, and the effects of $S$ are nonnegligible for the cases with high- $V_{f}$ values. Second, in terms of effects of $S$ on $n_{t}$ for a fixed $V_{f}$ and $Q$, two distinct trends exist: a positive dependence at low-flow rates and a decreasing trend at high-flow rates. These two trends are due to two conflicting impacts determining $n_{t}$ : when $S$ is increased, the friction slope $S_{f}$ grows, while the same is true for cases when the flow depth $h$ decreases. On the other hand, for a fixed $V_{f}$ and $S$, two distinct modes of the relationship between $Q$ and $n_{t}$ emerge: a positive dependence at mild slopes, and a negative dependence at steep slopes. A regression analysis shows that these two conflicting trends can happen depending on whether the variability of flow depth with respect to $S$ (or $Q$ ) is greater than the ratio of $h$ and $S$ (or $Q$ ). Third, a rougher bed with larger $n_{b}$ implies an increase of the form/wave resistances due to vegetation. Last, this study corroborates earlier research that $n_{t}$ grows as $h$ increases and decreases with higher V [Fathi-Moghadam, 2006].

\section{Notation}

$A$ area of triangular cell.

$A_{r}$ area of roughness element.

$C$ Chezy resistance factor.

$C_{D}$ drag coefficient.

$D_{r} \quad$ diameter of roughness element.

$E_{x}$ summation of bed elevation, depth, and velocity head.

$F_{r} \quad$ Froude number.

$Q$ inflow rate.

$Q_{\text {steady }}$ discharge at steady state.

$Q(t)$ discharge at time t.

$R$ hydraulic radius.

$R^{2} \quad$ coefficient of determination.

$R e$ Reynolds number.

$R_{r}$ roughness Reynolds number.

$S$ bed slope.

$S_{f}$ friction slope.

$S_{f, x} \quad x$ directional friction slope.

$S_{f, y} \quad y$ directional friction slope.

$\bar{S}_{f} \quad$ spatially averaged friction slope.

$V$ velocity magnitude.

$\bar{V} \quad$ spatially averaged velocity magnitude.

$V_{f}$ vegetation cover fraction.

$f$ Darcy-Weisbach friction factor.

$f_{f}$ form Darcy-Weisbach friction factor.

$f_{s}$ surface Darcy-Weisbach friction factor.

$f_{t}$ total Darcy-Weisbach friction factor.

$f_{w}$ wave Darcy-Weisbach friction factor.

$g$ acceleration due to gravity. 
$h$ flow depth.

$\bar{h} \quad$ Spatially averaged flow depth.

$k$ characteristic height of roughness element.

$n$ Manning roughness coefficient.

$n_{b}$ base Manning roughness coefficient.

$n_{t} \quad$ total Manning roughness coefficient.

$q$ discharge per unit width.

$t$ time.

$t_{c}$ time of concentration.

$u \quad x$ directional velocity.

$v \quad y$ directional velocity.

$z_{b}$ bed elevation.

$\mu$ dynamic viscosity of water.

$\rho$ density of water.

$\in$ a tolerance value used in equation (1).

[61] Acknowledgments. This study has been supported by the Graham Environmental Sustainability Institute at the University of MI through the grant "Assessment of the Impact of Watershed Changes on Estuarine Morphology and Aquatic Life". This work was also supported by the Rackham Merit Fellowship at the University of Michigan and a Graduate Fellowship of the Department of Civil and Environmental Engineering at the University of Michigan. Valeriy Ivanov was supported by NSF Grant EAR 1151443. The authors are grateful to D. Lawrence for her help with experimental data.

\section{References}

Abrahams, A. D., and A. J. Parsons (1994), Hydraulics of interrill overlandflow on stone-covered desert surfaces, Catena, 23(1-2), 111-140.

Abrahams, A. D., A. J. Parsons, and S. H. Luk (1986), Resistance to overland-flow on desert hillslopes, J. Hydrol., 88(3-4), 343-363.

Anderson, J. D. (1995), Computational Fluid Dynamics, McGraw-Hill, New York.

Begnudelli, L., and B. F. Sanders (2006), Unstructured grid finite-volume algorithm for shallow-water flow and scalar transport with wetting and drying, J. Hydraul. Eng., 132(4), 371-384.

Biron, P. M., S. N. Lane, A. G. Roy, K. F. Bradbrook, and K. S. Richards (1998), Sensitivity of bed shear stress estimated from vertical velocity profiles: The problem of sampling resolution, Earth Surf. Processes Landforms, 23, 133-139.

Blasius, H. (1913), Das Ähnlichkeitsgesetz bei Reibungsvorgängen in Flüssigkeiten, Forschungs Arb. Ing. Wes., 131, 1-41.

Bunte, K., and J. Poesen (1993), Effects of rock fragment covers on erosion and transport of noncohesive sediment by shallow overland flow, Water Resour. Res., 29, 1415-1424.

Chow, V. T. (1959), Open-Channel Hydraulics, pp. 680, McGraw-Hill, New York.

Cowan, W. L. (1956), Estimating hydraulic roughness coefficients, Agric. Eng., 37(7), 473-475.

Einstein, H. A., and R. B. Banks (1950), Fluid resistance of composite roughness, Eos Trans. AGU, 31(4), 603-610.

Emmett, W. W. (1970), The hydraulics of overland flow on hillslopes, U.S. Geol. Surv. Prof. Pap., 662-A, $68 \mathrm{pp}$.

Fathi-Moghadam, M. (2006), Effects of land slope and flow depth on retarding flow in non-submerge vegetated lands, J. Agron., 5, 536-540.
Ferro, V. (2003), Flow resistance in gravel-bed channels with large-scale roughness, Earth Surf. Processes Landforms, 28, 1325-1339.

Gilley, J. E., and S. C. Finkner (1991), Hydraulic roughness coefficients as affected by random roughness, Trans. Am. Soc. Agric. Eng., 34(3), 897903.

Gilley, J. E., E. R. Kottwitz, and G. A. Wieman (1992a), Darcy-Weisbach roughness coefficients for gravel and cobble surfaces, J. Irrig. Drain. Eng., 118, 104-112.

Gilley, J. E., D. Flanagan, E. R. Kottwitz, and M. A. Weltz (1992b), DarcyWeisbach roughness coefficients for overland flow, in Overland flow, edited by A. J. Parsons, and A. D. Abrahams, pp. 25-52, UCL Press, London.

Hessel, R., V. Jetten, and Z. Guanghui (2003), Estimating Manning's n for steep slopes, Catena, 54, 77-91.

Hirsch, P. (1996), Hydraulic resistance to overland flow on semiarid hillslopes: A physical simulation, Ph.D. dissertation, State Univ. of N.Y., Buffalo, N.Y.

Hu, S. X., and A. D. Abrahams (2006), Partitioning resistance to overland flow on rough mobile beds, Earth Surf. Processes Landforms, 31(10), 1280-1291.

Ivanov, V. Y., E. R. Vivoni, R. L. Bras, and D. Entekhabi (2004), Catchment hydrologic response with a fully distributed triangulated irregular network model, Water Resour. Res., 40, W11102, doi:10.1029/2004 WR003218.

Julien, P. Y., and D. B. Simons (1985), Sediment transport capacity of overland flow, Trans. Am. Soc. Agric. Eng., 28(3), 755-762.

Katopodes, N. D. (1982), On zero inertia and kinematic waves, J. Hydraul. Eng., 108, 1380-1387.

Kim, J., A. Warnock, V. Y. Ivanov, and N. D. Katopodes (2012), Coupled modeling of hydrologic and hydrodynamic processes including overland and channel flow, Adv. Water Resour., 37, 104-126.

Lawless, M., and A. Robert (2001), Scales of boundary resistance in coarse-grained channels: Turbulent velocity profiles and implications, Geomorphology, 39, 221-238.

Lawrence, D. S. L. (1997), Macroscale surface roughness and frictional resistance in overland flow, Earth Surf. Processes Landforms, 22(4), 365382.

Lawrence, D. S. L. (2000), Hydraulic resistance in overland flow during partial and marginal surface inundation: Experimental observations and modeling, Water Resour. Res., 36(8), 2381-2393.

Li, R. M., and H. W. Shen (1973), Effect of tall vegetations on flow and sediment, J. Hydraul. Div., 99(5), 793-814.

Nikuradse, J. (1933), Strömungsgesetze in rauhen Rohren, Forschungs Arb. Ing. Wes., 361, 1-22.

Phelps, H. O. (1975), Shallow laminar flows over rough granular surfaces, J. Hydraul. Div., 101(3), 367-384.

Rauws, G. (1988), Laboratory experiments on resistance to overland flow due to composite roughness, J. Hydrol., 103, 37-52.

Roels, J. M. (1984), Flow resistance in concentrated overland flow on rough slope surfaces, Earth Surf. Processes Landforms, 9, 541-551.

Savat, J. (1980), Resistance to flow in rough supercritical sheet flow, Earth Surf. Processes Landforms, 5(2), 103-122.

Smart, G. M., M. J. Duncan, and J. M. Walsh (2002), Relatively rough flow resistance equations, J. Hydraul. Eng., 128(6), 568-578.

Smith, M. W., N. J. Cox, and L. J. Bracken (2007), Applying flow restistance equations to overland flows, Prog. Phys. Geogr., 31, 363-387.

Stoesser, T., S. J. Kim, and P. Diplas (2010), Turbulent Flow through Idealized Emergent Vegetation, J. Hydraul. Eng., 136(12), 1003-1017.

Takken, I., and G. Govers (2000), Hydraulics of interrill overland flow on rough, bare soil surfaces, Earth Surf. Processes Landforms, 25(13), 1387-1402. 